\title{
Efficacy of Vacuum-Assisted Closure (VAC) in Wound Healing
}

\author{
Zeeshan Ahmed', Najam Husain², Shahd Nour², Sook Han Yee ${ }^{2}$ \\ ${ }^{1}$ Pakistan Institute of Medical Sciences, Islamabad, Pakistan \\ ${ }^{2}$ University Hospital of Derby and Burton, Derby, UK \\ Email:drnajamlp@gmail.com
}

How to cite this paper: Ahmed, Z., Husain, N., Nour, S. and Yee, S.H. (2019) Efficacy of Vacuum-Assisted Closure (VAC) in Wound Healing. Surgical Science, 10, 173-215.

https://doi.org/10.4236/ss.2019.106022

Received: May 15, 2019

Accepted: June 25, 2019

Published: June 28, 2019

Copyright () 2019 by author(s) and Scientific Research Publishing Inc. This work is licensed under the Creative Commons Attribution International License (CC BY 4.0).

http://creativecommons.org/licenses/by/4.0/

(c) (i) Open Access

\begin{abstract}
Introduction: Management of wounds is one of the commonest, often quite challenging as well, in surgical practice. Dressing is an essential component of wound management. Given its importance in achieving wound healing and its complications, methods of dressing have been under constant review since time immemorial. Many innovative techniques of wound dressing have been introduced for quick and problem-free wound healing. Vacuum Assisted Closure (VAC) is one of such methods. Objective: To determine whether VAC can help in reducing the healing time of open wounds. Study Design: Quasi-experimental study. Setting: Department of General Surgery, Pakistan Institute of Medical Sciences, Islamabad. Patients and Methods: 120 patients with open wounds, surgical or accidental, were included in the study. They were alternatively assigned to either VAC (Group I) 2 or WMD \{wet to moist dressing\} (Group II). In both groups, the wounds were assessed for surface area, depth and percentage of granulation every 48 hours for 15 days. Mean change in above wound parameters at the end of study period was calculated. The difference between the two groups was statistically analyzed by applying student $\mathrm{T}$ test. $\mathrm{P}$ value less than 0.05 was considered significant. Results: In Group I, at the end of the study period, mean reduction in the wound surface area and volume was $39.4 \%$ and $60.3 \%$ respectively, while granulation tissue formation was $59.7 \%$. In Group II, the respective figures were $26.9 \%, 38.2 \%$ and $24.5 \%$. The difference between the two groups was statistically significant $(\mathrm{P}<0.001)$. Conclusion: VAC was more effective than WMD in terms of reduction in wound surface, depth and degree of granulation tissue formation. VAC thus can be usefully employed for achieving speedy wound healing.
\end{abstract}

\section{Keywords}

Wound, VAC, NPWT, WMD3 


\section{Introduction}

All types of wounds, especially non-healing types, are one of the most common surgical conditions which a surgeon comes across. Whatever the management given, chronic wounds, especially diabetic ulcers or pressure sores refuse to heal. The issue of chronic wound management still remains an enigmatic challenge. The same applies to wounds occurring in an acute setting. Whether inflicted by accidental trauma or through planned surgical procedure, they universally require thousands of man hours in terms of their care. The creation of open wounds may become inevitable in certain circumstances. This demands greater care of these wounds as the longer the time needed to heal the longer it will be vulnerable to complications. These complications include bleeding, ulceration, infection and progression to chronicity to name a few. Empirically, the ancient physicians of Egypt, Greece, India and Europe developed gentle methods of treating wounds by removing foreign bodies, suturing, covering wounds with clean materials and protecting injured tissue from corrosive agents [1]. While Sumerian cuneiform tablets depicted poultices being applied to wounds 4000 years ago, the ancient Egyptians advanced this practice by creating dressings composed of vegetable fibers, grease, and honey to provide absorbency, barrier protection, and antimicrobial activity, respectively. Around $150 \mathrm{AD}$, the Greek physician Galen published the observation that wounds from gladiatorial combat healed optimally in a continuously moist environment [2] [3]. During the last two decades a wide variety of innovative dressings have been introduced. Traditional therapy of chronic, open wounds entails at least twice daily or more frequent and often painful dressing changes performed by skilled nursing staff. The VAC system provides a closed system with dressings that are changed every 48 hours. Rapid healing of chronic wounds could result in decreased hospitalization and an earlier return of function. A product that improves the healing process could greatly decrease the risk of infection, amputation, and length of hospital stay, and result in an estimated potential annual savings of billions of healthcare cost [4] [5].

\section{Literature Review}

A wound may be defined as any disruption of the integrity of skin, mucous membrane or organ tissue. A distinction is made between simple wounds that are confined to the skin, and complicated wounds which are deeper and also involve injury to muscles, nerves, and vessels [6]. Wounds can be caused by mechanical, thermal, chemical, and radiogenic trauma. The primary care of wounds is the task of the surgical disciplines. The monitoring of wounds and application of further wound dressings, however, can be carried out by all physicians and may also be delegated to nursing personnel. The primary goals of all wound management are rapid wound closure and a functional and aesthetically satisfactory scar. Delay in wound healing poses the risk of additional wound complications like infection and disruption. It is a major contributor towards morbidity 
of surgical patients, adds to the cost of treatment and consumes a lot of hospital resources. Many patients with non-healing wounds complain of difficulties with emotions, finances, physical health, daily activities, friendships, and leisure pursuits [6]. To arrive at a better understanding of man's endeavor to achieve satisfactory and rapid wound closure we must have some basic knowledge regarding wounds and their management. The first step in this regard is a simple classification system [7].

These divide wounds into:

Surgical incisions: They cause minimal tissue damage because they are made with precision in a controlled setting where aseptic techniques reduce the risk of infection, with fine instruments and the facility to control bleeding.

Penetrating trauma: This imparts minimal damage to skin and sub-cutaneous tissue, though more extensive damage to vessels, nerves and internal organs may be present.

Lacerations. These occur when there is high energy transfer exceeding intrinsic tissue strength e.g. skin damaged by blunt injury over a bony prominence such as the cranium. Damage may not be extensive, and primary closure with stitches may be possible. Skin staples may be suitable in some instances e.g. in pre-tibial laceration, because stitching causes excessive tension, with the edema healing and inflammation resulting in more tissue loss.

Contusions: These are a result of more widespread tissue trauma after severe blunt or blast injury. The skin above the injury may seem to be healthy but later may become necrosed. Large subcutaneous [7] or intra-muscular hematomas may coexist. If they are near the surface and are fluctuant they can be removed with overlying dead skin. Radiological imaging may help to identify a hematoma amenable to drainage. Massive contusion may become infected therefore antibiotic prophylaxis is essential in open wounds. There may be formation of compartment syndrome which will require a fasciotomy to be performed to preserve a limb.

Large open wounds. These wounds are preferably left to heal by "secondary intention" which means that the wound heals from the base upwards, by build-up of new tissue. In some cases, delayed skin grafting may be required depending on the residual defect after conservative treatment. Exploration of such a wound is essential if there is a suspicion of vascular or neuronal damage, paying special attention to fractures. All de-vascularised tissue should be debrided and foreign bodies should be removed.

Abrasions: Superficial epithelial wounds resulting from frictional forces are called abrasions. When extensive, there may be associated fluid loss. These injuries should be cleaned by irrigating with normal saline or clean water to minimize chances of infection, and foreign material on the surface of such wounds should be manually removed to avoid unattractive "tattooing".

Table 1 forms a classification of traumatic and surgical wounds [7]. Another type of classification system based on the extent of contamination of surgical 
Table 1. Types of traumatic and surgical wounds.

\begin{tabular}{ccc}
\hline Type of wound & Result & Cause \\
\hline Incision & Penetrating & Surgical, Trauma \\
Laceration & Torn tissue & Trauma \\
Contusion & Extensive tissue damage & Trauma, skin may be intact \\
Abrasion & Superficial epithelial & Trauma \\
Combination & Life threatening & Severe trauma \\
\hline
\end{tabular}

wounds is also frequently used. The risk of wound infection and consequent delayed wound healing is directly proportional to the amount of microbial load. It also dictates the need for antibiotic prophylaxis [8] [9]. The classification divides wounds into the following categories.

Clean wound is where No viscus is opened. Microbial contamination is minimal or none at all. There is a $2 \%$ risk of wound infection. Antibiotic prophylaxis is not required for non-prosthetic surgery. Examples include hernia repair, varicose veins, breast surgery, prosthetic surgery including vascular and orthopaedic implants [10].

Clean contaminated surgery entails opening of a hollow viscus where there is impending or minimal spillage of its contents. Without antibiotic prophylaxis infection rates can approach up to $20 \%$ for biliary surgery and $30 \%$ for gastric surgery. After the advent of antibiotic prophylaxis rates have fallen to levels below $10 \%$.

Contaminated wounds are seen in operations where a hollow viscus is opened and there is gross spillage. Other instances are where generalized inflammatory disease is encountered. Infection rates are in the $15 \%$ to $20 \%$ range with prophylactic antibiotics. Without prophylaxis the risk of infection may exceed $40 \%$. Examples [10] are elective colorectal procedures where prophylactic antibiotics are essential [11].

Dirty Surgery in which an incision has to be made through an abscess is defined as dirty surgery. There may also include a pus-filled body cavity or a long-standing viscus perforation e.g. drainage of an abscess or faecal peritonitis. Infection rate with antibiotic coverage is less than $40 \%$ but may be approach $60 \%$ without.

Table 2 categorizes wounds and the requirement of prophylactic antibiotics according to their level of contamination [12].

Table 3 describes how wounds should be managed with the plan of secondary healing or delayed primary closure [7].

After becoming familiar with the definition and types of wounds we arrive at the physiology of wound healing to better manage them [13]. It is an extremely complex sequence of events and follows multiple overlapping phases. Wound healing has been the subject of research for more than 100 years. Evolving research in molecular biology in contemporary times has given increased insights into the basic processes involved. It has revealed that the most important 
Table 2. Categories of surgical wounds according to contamination.

\begin{tabular}{|c|c|c|}
\hline Category & Example & Prophylactic Antibiotic \\
\hline Clean & $\begin{array}{c}\text { Hernia } \\
\text { Varicose vein } \\
\text { Breast } \\
\text { Prosthetic } \\
\text { Vascular } \\
\text { Orthopaedic }\end{array}$ & $\begin{array}{l}\text { Needed specially in } \\
\text { prosthetics }\end{array}$ \\
\hline Clean-contaminated & Elective cholecystectomy & Needed \\
\hline Contaminated & Elective colorectal operations & Needed \\
\hline Dirty & Abscess drainage Faecal peritonitis & $\begin{array}{l}\text { Needed and continued } \\
\text { after operation }\end{array}$ \\
\hline
\end{tabular}

Table 3. Types of wounds to be considered for open management.

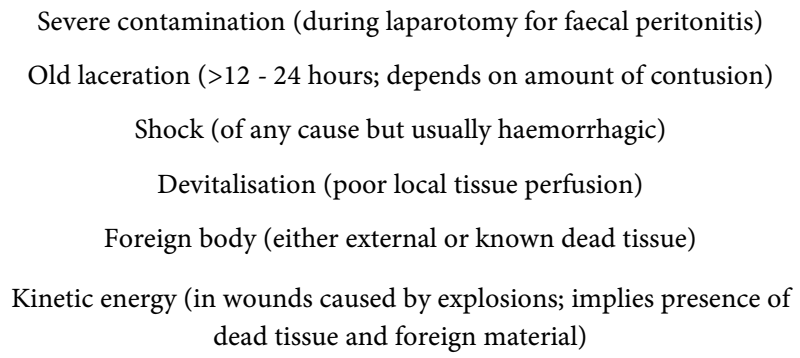

management guideline in all practicality is to sustain the natural course of wound healing without endangering it through wrong and unwanted manipulations. The process of healing traditionally divided into four phases namely: The process of healing traditionally divided into four phases namely:

- exudative phase

- resorptive phase

- proliferative phase

- regenerative phase

Recently wound healing has been separated into three phases only according to immunological aspects:

- inflammation

- proliferation

- wound modulation/re-modelling

We have preferred the more practical and traditional classification.

Exudative phase This phase is hallmarked by the formation of fibrin and migration of platelets which coalesce to form a physical clot. In the phase, the platelets express various mediators of healing known as growth factors [14]. These work to activate cells of inflammation i.e. macrophages and fibroblasts. Further processes are controlled by the growth factors already released and by cytokines, which herald the arrival of cellular structures [15]. Numerous cytokines, more than 30 , have so far been identified, and are released by all types of 
cells ranging from macrophages, platelets, fibroblasts, epidermal cells, and neutrophils [16] [17].

Resorptive phase The products of degradation of fibrin cause activation of chemotaxis in this phase. After about 1 to 2 days, leukocytes and macrophages move to the wounded area causing inflammation. These cell products are able to autolyze and remove dead tissue by decaying processes. Overall, an intricately coordinated system of phagocytosis, defence, and immune system is brought about.

Proliferative phase After 48 hours extending up to 1 week, influx of fibroblasts with neo-angiogenesis occurs during the proliferative phase. The most visible characteristic of this phase is the formation of granulation tissue. Cells of the epidermis grow from the margins of the wound inward and a noticeable fine border forms [18]. This proliferative phase is also regulated by the growth factors and cytokines mentioned previously. The fibroblasts create a fresh extracellular matrix. The fine blood vessels that have formed supply the healing margins with the necessary oxygen for metabolism [19]. The initial clot is lysed by factors of the fibrinolysis system i.e. u-PA (urokinase plasminogen activator) and t-PA (tissue plasminogen activator). The different matrix metalloproteinases (MMP) refashion the extracellular matrix.

As expected, these processes can only occur in a coordinated fashion if activation and inhibition reactions take place in an equal ratio to each other. The complex remodelling of the tissue of migration fibroblasts and capillaries into a planned extracellular matrix requires a tender approach when dressings the wound.

Regenerative phase This phase may continue from months to years. The maturating of collagen leads to an increase in the wound's tensile strength. The major features of this phase are epithelization and the formation of the scar. Remodelling and restructuring are also continuously going on during this phase. For example, type III collagen is turned into type I collagen of the more mature wound. The relationship between the extracellular matrix and cell organelles of the wound are controlled by cell membrane receptors called integrins and by cytokines. Besides the two pathological stages of wound healing mentioned above, there is also a third classification, which divides wound healing into primary wound healing "sanatio per primamintentionem (healing by primary intention)" and secondary wound healing "sanatio per secundamintentionem (healing by secondary intention)".

Primary wound healing is the straightforward process of healing of un-infected, well-adapted wounds. If at any stage this process is derailed by any of a multitude of factors that affect wound healing, a situation of secondary wound healing develops. These adverse factors are detailed subsequently.

Every wound should be examined preferably once a day during the initial post-operative period. The most frequently encountered problems one can face in this time are infection and secondary bleeding. Infection can be suspected 
readily by observing the classical features of inflammation i.e. dolor, rubor, calor, and tumor. If signs of the emergence of an abscess are seen, adequate exposure by incision should be done to evacuate the pus and then subjecting the wound to adequate irrigation. Anesthesia is a pre-requisite for this followed by pain relief. Hematomas, no matter in which shape, can be left alone if its volume is between 50 to $200 \mathrm{ml}$ keeping in mind the size of the wound. Outcome with intervention in terms of healing and time to closure will only improve if hematomas are large compared to the wound. Since a clean wound healing with primarily intent closes soon due to strong linking of fibrin, moderate mechanical washing can be initiated as early as after 24 hours. These types of wounds can be cleaned after 24 hours with normal saline to remove dead tissue and remnants of the surgical disinfectant. The defect should be irrigated with a mild antiseptic. To physically protect the wound, a dressing can then be applied. The application of an appropriate dressing can be very comforting to the patient. Wound clips or stitches may be removed after consultation with the treating surgeon. Removal of these is also determined by the local condition of the wound and general blood circulation in the region of the body. The factors that should be kept in view when removing stitches are co-morbidities such as diabetes mellitus, immunosuppressive states, high tension in the skin in closure of defects or local swelling. All these may make it prudent to leave the sutures in place for longer.

Secondary wound healing The most important rule of wound care in secondary wound healing is to make it sure that a situation is present to provide the wound with a moist, physiological environment. The gases in air and most notably especially oxygen are harmful to the growing cells and in case the wound becomes dry it inevitably leads to gross tissue damage which may cause necrosis especially in tissues with poor blood supply (bradytrophic).

The second cardinal rule is to comply with the basic need of aseptic techniques in wound care. An exposed wound is bound to be infested with pathogenic microorganisms capable of producing disease. Wound dressings act as a physical barrier to allow the wound to recuperate from previous infection and to prevent further colonization of the wound from the environment.

For tender and painful wounds, adequate and appropriate analgesia should be a part of the change of dressing. Oral analgesics are usually enough in most cases depending on the magnitude of the wound. The most commonly used are non-steroidal anti-inflammatory drugs (NSAIDs), metamizole, paracetamol or COX-2 inhibitors. These medicines should be given prior to the procedure to take their effect. Studies have shown that good results are obtained with local analgesia with an ointment mixture of lidocaine and prilocaine. Good exposure time of about one hour should be allowed [20] [21]. A wound swab for microbiological studies should be taken in all cases at the start of wound treatment. It should be analyzed for gram positive, gram negative and anaerobic microorganisms. In high-risk patients e.g. age more than 75 years, diabetes mellitus, immunocompromise state, or prolonged hospitalization, the patient should be 
screened for methicillin-resistant Staphylococcus aureus (MRSA) strains. An open wound with good drainage does not generally need antibiotic treatment. If signs of sepsis i.e. fever, leukocytosis, and rise in CRP, are present the wound should be critically re-examined and appropriate revision of the wound should be undertaken to avoid infection. In the presence of elevated inflammatory parameters systemic antibiotic therapy should be initiated (if two of the parameters are positive). The recommended antibiotics are aminopenicillin with a $\beta$-lactamase inhibitor, a group 1 and 2 cephalosporin or a group 4 fluoroquinolone. Antibiotic therapy should also be considered in the presence of immunocompromised states, i.e. in patients after transplantation or with diabetes mellitus or patients undergoing chemotherapy. Occasionally an inflammation seen as redness, swelling and pain is there in the wound edges. If the underlying tissue is also infiltrated, a phlegmon is present. This inflammation requires very strict monitoring. Most surgeons agree on the use of antimicrobial therapy in such cases.

The chronic wound If the wound healing processes last for longer than four weeks and no tendency to healing is apparent, the wound is defined as having progressed to a chronic state. It is imperative to look for the cause of the wound healing disorder without delay. A chronic wound may be recognized by specific molecular markers [22] [23].

In all courses of wound healing problems may be encountered. There are several factors which may contribute to alteration in wound healing whether it is healing by primary intention or secondary intention. These factors can be summarized as Site of the wound is important in respect of tension along wound margins and the mobility of that specific location. Wounds around tension areas and joints tend to heal later than a wound on other locations. Secondly certain areas of the body have a relatively poor blood supply and have to withstand greater pressure which may be detrimental to wound healing. Structures involved dictate the period required for the wound to heal completely. The more the depth of the wound the more structures will be involved including muscles, tendon and bone. And the more the number of structures involved the more time they will take to heal. Tendons and bones are especially notorious in this respect. Mechanism of injury also determines the path the process of wound healing will follow. As mentioned previously the management of different types of wounds is dependent on their type. Incisional and penetrating wounds with clean margins heal without sequel compared to crush injuries with ragged margins. Contamination and foreign material including bacteria may be a source of continuous irritation and infection. Even suture materials have been found to act as local irritants and can hamper wound healing [24]. Presence of all or any of the above may lead to an acute wound into becoming a chronic one.

Loss of tissue is an obvious determinant of the rate of wound healing. If there is loss of tissue instead of just disruption, primary healing may be impossible. Secondary healing with its accompanying delay in closure and poor cosmetic 
result will be inevitable.

Vascular insufficiency During embryonic development, the vasculature is among the first organs to form and is in charge of maintaining metabolic homeostasis by supplying oxygen and nutrients and removing waste products. As one would expect, blood vessels are critical not only for organ growth in the embryo, but also for repair of wounded tissue in the adult. Diminished peripheral blood flow and decreased local neovascularization are critical factors that contribute to the delayed or non-healing wounds in some patients e.g. diabetics. Decreased blood flow also leads to decreased migration of inflammatory cells to the injured area. Poor lymphangiogenesis may also play a role in poor wound healing. Previous radiation has traditionally been associated with skin damage and delayed wound healing. Initially thought to be due to damage to skin fibroblasts, other factors are also being investigated to better understand effects of previous radiation on the injured skin [25].

Pressure areas are especially susceptible to wounding. This is due to poor vascular flow and poor drainage of exudates from the area. Malnutrition Nutrition is a critical component in all the wound healing processes. The stress response to injury and any pre-existent protein-energy malnutrition will alter this response, impeding healing and leading to potential severe morbidity [26]. A decrease in lean body mass is of particular concern as this component is responsible for all protein synthesis necessary for healing. Apart from nutritional assessment the use of anabolic agents can significantly increase overall lean mass synthesis and improves healing by increasing protein synthesis [27]. Deficiency of trace elements, minerals and vitamins are similarly essential in the process.

Diseases, such as diabetes, are notorious in delaying wound healing [28]. Vascular insufficiency is one of the primary causes of this delay apart from many other factors. Apart from diabetes, hypothyroidism, hepatic storage diseases and malignancy may also cause delayed wound healing [29].

Medications Vasoconstrictors, such as nicotine, cocaine, adrenaline (epinephrine) and ergotamine, cause tissue hypoxia by adversely affecting the microcirculation, leading to impaired wound healing. They should be avoided in patients with acute, surgical, or chronic wounds. Patients taking immunosuppressants, however, have a slightly increased risk of developing malignant ulcers. Hormone replacement with oestrogen may lead to poor wound outcomes [30] [31]. Administration of morphine to painful wounds has a time dependant adverse effect on wound healing [32].

Immune deficiency secondary to AIDS or systemic disease has a controversial role in wound healing. Immune deficiency secondary to drugs has a definite part to play in case where infections are encountered.

Smoking may be responsible for problems in wound healing. Preoperative smoking cessation has been suggested to be effective in reducing various postoperative complications [33]. For example, independent of other risk factors, smoking is predictive for post-mastectomy wound infection, skin flap necrosis, 
and epidermolysis [34].

Anger Certain patterns of anger expression have been associated with maladaptive alterations in cortisol secretion, immune functioning, and surgical recovery. It has been suggested that the ability to regulate the expression of one's anger has a clinically relevant impact on wound healing [35].

To avoid the untoward effects of all the factors mentioned previously we must come up with a multi-disciplinary approach to wound management [36]. Rational, evidence-based therapy can expedite the whole process [37] [38]. As mentioned earlier all that is to be done is to bolster the natural chain of events and not to intervene unnecessarily. Incised surgical and traumatic wounds can be closed by sutures, metal clips, staples, adhesive strips, methacrylate superglues, fibrin glues and laser heat sealing [39]. Although clean incised wounds can be closed primarily without untoward consequences, the real challenge is the management of large open wounds which may harbour foreign material and microorganisms. Management of wounds has had a chequered history. It has come a long way since the times when in 1346 at the Battle of Crécy, France, foot soldiers were issued with cobwebs to staunch haemorrhage caused by trauma. Surgeons even used a mixture of oil of turpentine, rosewater, and egg to dress wounds after amputations [7]. When the cause of the injury is high velocity (for example, blast or firearm), there is great damage due to the distribution of kinetic energy. Apart from major bony injury there may be gross muscle injury as well due to the cavitation effect of the missile. The soft tissue becomes ischemic and a very large exit wound may result. Clothing and other contaminants may be sucked into the wound because of the suction effect of the bullet. A relatively avascular environment along with foreign material serves as an ideal setting for anaerobic microbes e.g. Clostridium perfringens, which can lead to gas gangrene. These types of wounds require extensive debridement until healthy tissue is seen and have to be left open to heal until new tissue starts forming. To achieve this, debridment may have to be repeated. Despite meticulous cleaning of the wound infection may still occur mandating antimicrobial therapy. In the presence of a crush injury more extensive surgery is required. In these cases, fasciotomy may be very helpful in saving the patient's life and limb. After debridement, delayed closure or reconstructive surgery may be done. On the other hand, if the type of wound or area of body allow, the wound may be left open to allow it to heal by secondary intention. Examples of this type of injury include human and animal bites. Despite great strides in technological innovations and the emergence of a wide range of treatments, all types of wounds continue to tax the abilities and patience of doctors. Many non-surgical techniques have been developed and an even more diverse range of medications have been developed to manage wounds. Bandages and hosiery Compression bandages have been used since a long time to manage lower limb ulcers due to venous diseases (venous leg ulcers) and lymphoedema. Elastic bandages are divided into four groups in regard to the compression they provide. Inelastic compression bandages, when applied at full 
extension, augment the action of the calf muscle pump and exert greater pressures when the patient is standing and walking and less pressures lying down. They are used in mobile patients. A multi-layered bandage is also useful; however, the bulkiness of these layers may lead to non-compliance in some patients. Medicated bandages such as zinc paste bandages containing calamine, coal tar, or ichthammol can be effective in eczema and cellulitis [40]. Medicated bandages provide no compression. Intermittent pneumatic compression is effective in treating longstanding venous leg ulcers associated with severe oedema that is refractory to conventional compression therapy alone. Intermittent pneumatic compression provides compression (range $20-120 \mathrm{~mm} \mathrm{Hg}$ ) at pre-set intervals (average 70 seconds) through an electrically inflatable "boot" of variable lengths to improve venous and lymphatic flow. Hyperbaric oxygen the use of hyperbaric oxygen has been recommended as an adjunctive therapy to treat a variety of chronic wounds as many non-healing tissues are hypoxic. Biosurgery (myiasis) Biosurgery uses sterile maggots (usually of the green bottle fly, Luciliasericata), which digest loose and necrotic material from wounds preserving the underlying healthy tissue [41]. They have been shown in small scale trials to be useful in the treatment of venous, arterial, and pressure ulcers. The adverse effects are complaining of pain in the wound. Patients may develop psychological discomfort and many are concerned about the aesthetics. Other approaches Other non-surgical approaches that have withstood the test of evidence-based medicine basis and have been recommended for the treatment of wounds include radiant heat dressing, ultrasound therapy, laser treatment, hydrotherapy, electrotherapy, electromagnetic therapy, and PUVA therapy (psoralen plus ultraviolet A irradiation).

\section{Drugs}

Pentoxifylline, a methylxanthine that improves perfusion of peripheral vascular beds, is useful in patients with ulcers secondary to peripheral vascular disease. It improves capillary microcirculation by decreasing blood viscosity and reducing platelet aggregation. It may also inhibit tumour necrosis factor- $\alpha$, an inflammatory cytokine involved in non-healing wounds. Iloprost, a prostacyclin analogue, is an established treatment for intermittent claudication, severe limb ischaemia, and prevention of imminent gangrene, and to reduce the pain and clinical symptoms associated with Raynaud's disease. Intravenous iloprost is useful in promoting healing of vascular related. Antimicrobials including iodine-based preparations and silver releasing agents are used to treat infected wounds (there may be a dose-dependent effect). Antimicrobial agents target bacteria at cell organelle level. They can be used either on their own or in conjunction with systemic antibiotics. The many silver releasing agents, in dressing form, aim to deliver sustained doses of silver to the wound. In addition to the microbicidal effect of silver on common wound contaminants, silver may also be effective against methicillin resistant Staphylococcus aureus (MRSA) [42]. 
Glyceryl trinitrate, a nitric oxide donor, is effective in the management of chronic anal fissures when applied topically as $0.2 \%$ ointment. Nitric oxide causes vasodilatation, and uncontrolled studies have suggested a potential role for glyceryl trinitrate in treating wounds of ischemic etiology. Calcium antagonists such as diltiazem and nifedipine are useful in treating vasculitic ulcers secondary to Raynaud's disease and connective tissue diseases. They restore blood flow to the digits, and can treat and prevent necrosis in the extremities. Systemic corticosteroids are useful in treating ulcers secondary to connective tissue diseases, including rheumatoid arthritis, scleroderma, and other vasculitic disorders. They promote healing by attenuating the excessive inflammatory response. However other studies have shown that steroids can act as a double-edges sword. Excessive steroids may be detrimental to the healing process. In fact preventing local regeneration of glucocorticoids by $11 \beta$-hydroxysteroid dehydrogenase type 1 enhances angiogenesis [43]. Other drugs Zinc is an antioxidant used in a paste bandage. Phenytoin, applied topically, promotes wound healing by inhibiting the enzyme collagenase. Retinoids (derived from vitamin A) have an impact on wound healing through their effects on angiogenesis, collagen synthesis, and epithelialisation. Analgesics are needed for many ulcers. They may range from simple analgesics to opiates in individuals whose the pain is severe. However, caution has to be exercised when administering topical opioids regarding their adverse effects in the healing wound. Pain from ulcers associated with neuropathy may benefit from treatment with certain tricyclic antidepressants (such as amitriptyline) or antiepileptic drugs (such as gabapentin). Intractable pain may necessitate intervention by specialist pain management teams. ATP-encapsulated fusogenic small unilamellar lipid vesicles help wounds heal faster providing better development of granular tissue and re-epithelialization by increasing wound tissue vascular endothelial growth factor (VEGF) expressions [44]. GM-CSF when used clinically via the systemic circulation increases the circulating neutrophils. It may be useful for creating better wound healing and may be useful in risky patients such as diabetics [45]. Pluripotent growth factor molecules Wound repair involves the sequential interaction of various cell types, extracellular matrix molecules, and soluble mediators. New information on signals controlling wound cell behaviour has led to the use of local delivery of pluripotent growth factor molecules to the injured tissue. A molecular approach in which genetically modified cells synthesize and deliver the desired growth factor in regulated fashion has been used to overcome the limitations associated with the (topical) application of recombinant growth factor proteins [46]. Placental growth factor, an angiogenic mediator promoting pathophysiological neovascularization, is expressed during cutaneous wound healing and improves wound closure by enhancing angiogenesis. PlGF treatment stimulates cultured dermal fibroblast migration, pointing to a direct role of PlGF in accelerating granulation tissue maturation. Reduced PIGF expression contributes to impaired wound healing in diabetes and PlGF gene transfer to diabetic wounds exerts therapeutic activity by 
promoting different aspects of the repair process [47]. Stem cells and Natural origin biodegradable systems Advanced therapies use the knowledge of regenerative medicine coupled with appropriately tissue-engineered skin substitutes. Natural biopolymers such as collagen and fibronectin are being investigated as potential sources of biomaterial to which cells can attach. Recent advances in the use of DNA microarray and proteomic technology are likely to aid development of appropriate delivery molecules to do so. The fields of tissue engineering and regenerative medicine aim at promoting the regeneration of tissues or replacing failing or malfunctioning organs, by means of combining a scaffold/support material, adequate cells and bioactive molecules. Different materials have been proposed to be used as both three-dimensional porous scaffolds and hydrogel matrices for distinct tissue engineering strategies. Among them, polymers of natural origin are one of the most attractive options, mainly due to their similarities with the extracellular matrix (ECM), chemical versatility as well as typically good biological performance [48] [49]. Natural products Honey, of the pasture and manuka varieties, has some antibacterial action, inhibits excessive inflammatory response, and promotes autolytic debridement. It is available as an impregnated dressing or as a gel. Honey is used in the treatment of a range of chronic wounds. Clinical data to support its widespread use are limited, however, with insufficient evidence on the type of wounds that may benefit and the amount and duration of application required [50] [51] [52]. Many other natural products-including vinegar, yoghurt, tea tree oil, and potato peeling-have been used in various parts of the world to treat ulcers with varying degrees of success [53]. Whatever is done in the initial management of any wound eventually it has to be dressed, whether be it a sutured laceration or an open wound. A dressing has to be as close to an ideal one as possible. The table on the following page outlines some features of a perfect dressing.

Traditionally wet-to-dry gauze has been used to dress wounds. Dressings that create and maintain a moist environment, however, are now considered to provide the optimal conditions for wound healing. Moisture created by occlusive dressings actively increases the rate of epithelialisation and also helps healing through moisture and the presence of a low oxygen tension making the inflammatory phase possible. Gauze lacks these properties and in fact it may be more disruptive to the healing wound as it becomes dry and results in tissue damage when the dressing is changed [54] [55]. Occlusive dressings increase cell division and migration by retaining an optimum level of wound exudate, which provide the healing wound with all the vital proteins and growth factors expressed in response to injury. These promote autolytic cleaning of the wound and facilitate healing [37]. Low adherence dressings are relatively cheap and easily available. They act by allowing the exudate to move through into a secondary dressing while still retaining vital moisture in the wound bed [54] [56] [57]. They are available in the shape of tulles, which are open weave cloth soaked in soft paraffin or chlorhexidine. They are intended to reduce adherence to the wound bed 
and are especially useful for patients with vulnerable or fragile skin [58]. Semipermeable films are a major advancement in wound therapy and have caused a major change in wound management. They constitute of sterile synthetic sheets of polyurethane covered with acrylic adhesive and are found their major use as a transparent primary wound cover. They are impermeable to all types of fluids and microorganism but allow air and water vapor to pass through freely. This depends on the moisture and vapor transmission rate which is pre-determined by each brand. This is the mechanism by which a controlled moist and sterile wound environment is created. The dressing is very flexible and can be applied on the most difficult of body areas and can be customized for each type of wound dimension. However, they cannot divert the fluid from a heavily exudating wound and may cause damage to the surrounding skin if it is used unnecessarily in these cases. Hydrocolloids Sodium carboxymethylcellulose, gelatin, pectin, elastomers, and adhesives are bonded to a carrier of semipermeable film or a foam sheet to produce a flat, occlusive, adhesive dressing that forms a gel on the wound surface, promoting moist wound healing. This gel, which may become yellow and malodorous may be appear like wound infection to the lay person. They are impermeable to water vapour and air and prevent evaroporation of moisture from dry wounds such as necrotic eschar and thus help autolytic debridement. They are helpful in reducing pain and allow the patient to cleanse themselves with water to lead a normal lifestyle and perform daily activities with ease without risking contamination of the wound [56] [59].

Hydrogels consist of a matrix of insoluble polymers with up to $96 \%$ water content enabling them to donate water molecules to the wound surface and to maintain a moist environment at the wound bed. As the polymers are only partially hydrated, hydrogels have the ability to absorb a degree of wound exudate, the amount varying between different brands. They transmit moisture vapour and oxygen [56]. They promote wound debridement by rehydration of dead tissue, thus helping natural autolysis. Amorphous hydrogels are the most commonly used and are thick, viscous gels. Hydrogels are considered to be a standard form of management for sloughy or necrotic wounds [59]. Alginates are produced from the naturally occurring calcium and sodium salts of alginic acid found in a family of brown seaweed (Phaeophyceae). They generally fall into one of two kinds: those containing $100 \%$ calcium alginate or those that contain a combination of calcium with sodium alginate, usually in a ratio of 80:20. Alginates partly dissolve on contact with wound fluid to form a hydrophilic gel as a result of the exchange of sodium ions in wound fluid for calcium ions in the dressing. Alginates can absorb 15 to 20 times their weight of fluid, making them suitable for highly exuding wounds [54] [58]. Foam dressings are manufactured as either a polyurethane or silicone foam. They transmit moisture, vapour and oxygen and provide thermal insulation to the wound bed. They facilitate uniform dispersion of exudate throughout the absorbent layer and prevent exterior leakage due to the presence of a semipermeable backing. The major advantage of 
foam is the ability to contain exudate. In addition, foam dressings protect the area around the wound from further damage. They are also available as a cavity dressing; small chips of hydrophilic polyurethane foam enclosed in a membrane of perforated polymeric film, giving a loosely filled bag [56]. Antimicrobial dressings Silver, in ionic or nanocrystalline form, has for many years been used as an antimicrobial agent particularly in the treatment of burns (in the form of silver sulfadiazine cream). The recent development of dressings impregnated with silver has widened its use for many other wound types that are either colonised or infected. Iodine also has the ability to lower the microbiological load. Metronidazole gel is often used for the control of odour caused by anaerobic bacteria. This is particularly useful in the management of fungating malignant wounds. It may be used alone or as an adjunct to other dressings. Vacuum Assisted Closure In the end we come to a relatively new form of wound therapy. This type of dressing was studied in my trial because it has shown very promising results in our patients. Vacuum assisted closure involves placing a piece of foam over the wound, thereby creating a suction effect and subjecting the entire wound area to negative pressure. This technique combines three principles of wound treatment:

- wound cleansing by continuous drainage

- modification of the wound environment and reduction of bacterial colonization, and

- maintaining a moist environment

Vacuum sealing is indicated for surgically debrided wounds in the proliferative phase. Heavy exudation and deep wound pockets can be effectively treated by the inserted sponges. This creates a practicable, hygienic situation for the patient and his environment. Although its application requires specialized knowledge and skill, it requires less labour on the part of the nursing staff. Vacuum therapy can also be performed in the outpatient setting.

Due to this negative pressure wound therapy has become an increasingly important part of wound management. Over the last decade, numerous uses for this method of wound management have been reported, ranging from acute and chronic wounds, to closure of open sternal and abdominal wounds, to assistance with skin grafts. The biophysics behind the success of this treatment largely have focused on increased wound blood flow, increased granulation tissue formation, decreased bacterial counts and stimulation of wound healing pathways through shear stress mechanisms. The overall success of negative pressure wound therapy has led to a multitude of clinical applications. Timmers et al. in their prospective, randomized study evaluated the response of cutaneous blood flow (CBF) in healthy intact forearm skin to varying VAC [60]. Continuous negative pressure was used in the range of $25-500 \mathrm{~mm}$ Hg. Skin blood flow was measured with non-invasive laser Doppler probes incorporated into the foam. Significant increase in CBF was found with both foams up to negative pressure of $300 \mathrm{~mm} \mathrm{Hg}$, with 3 to 5 -fold increase. Comparison of blood flow at baseline and 
at a negative pressure of $300 \mathrm{~mm} \mathrm{Hg}$ showed a statistically significant difference $(\mathrm{P}<0.001)$. No decrease in blood flow below baseline was observed during the experiments. The exact mechanism of action of vacuum dressing is diverse and many theories exist. The first is based on the stimulatory effect of microstrain on cellular mitogenesis, angiogenesis, and elaboration of growth factors. This is the same mechanism that is operational in controlled Ilizarovian distraction or in tissue expansion. The second is based on the enhancement of the dynamics of microcirculation by active evacuation of excess interstitial fluid in the form of edema. Physiologically, there is a lowering of the heightened capillary afterload and a qualitative dilution of contained microcontaminants, bacteria, and proinflammatory cytokines. Based on these effects, the use of vacuum dressing has found a place in the management of high-energy traumatic wounds and certain high-risk elective surgical wounds [61]. It is also hypothesized that tissue deformation due to negative pressure applied to them stretches individual cells, thereby promoting proliferation in the wound microenvironment. The application of micromechanical forces may be a useful method with which to stimulate wound healing through promotion of cell division, angiogenesis, and local elaboration of growth factors [62]. Another major finding has been the knowledge that with negative pressure, reductions in levels of the pro-inflammatory cytokine, TNF- $\alpha$, from baseline levels were observed and this effect is sustained for some period. This, together with effects on IL-1 and MMP-3, may be an indication that the NPWT has a rapid and sustained effect on the inflammatory state of chronic wounds. These facts suggest that vacuum dressing may be more clinically effective in reducing wound volume, compared with advanced moist wound healing. Furthermore, the lower cost per cubic centimetre volume reduction suggests that vacuum assisted produces a more favourable cost-effective solution [63]. Some special tips regarding application of this technique may be used to optimize the effect [64]. A single VAC dressing can be used for multiple separate wounds. After applying the VAC sponge and occlusive dressing to the individual wounds, the VAC suction tubing is adhered to the main wound. The tubing is then incised at sites corresponding to the smaller wounds and occlusive dressing used to obtain an air-tight seal over each dressing. The VAC pump is then able to produce negative pressure across multiple small wounds in series. To obtain an air-tight seal in hair-bearing or sweaty regions such as the perineum, it is useful to lay the occlusive VAC film onto hydrocolloid dressings, which seem to adhere more strongly to these areas. Putting some lignocaine into tube before removing dressing causes less pain. Applying Compound Benzoin Tincture to the skin surrounding the wound, letting it dry and then applying the adhesive dressing give it a better adhesion.

\section{Objectives}

The objective of the study is to determine whether VAC can help in reducing the healing time of open wounds. 


\section{Operational Definition}

Wound-an open wound on the trunk and limbs, which will not be able to heal by primary intention.

Efficacy-efficacy will be determined by observing the rate of granulation of the wound by measuring the granulation tissue as a percentage of ulcer bed and the time taken for healing to occur.

It will be measured by filling out a proforma (annexed).

Vacuum Assisted Closure (VAC) - a method of dressing which entails application of negative pressure to a wound in a closed environment to promote healing.

Wet to moist dressing (WMD)—conventional method of wound dressing in which wounds are cleaned with normal saline and covered with sterile gauze.

\section{Hypothesis}

The hypothesis is that Vacuum-Assisted Closure technique in the management of open wounds is a better surgical option than wet to moist dressings.

\section{Materials and Methods}

SETTING Inpatient section of the Department of General Surgery Unit II, Pakistan Institute of Medical Sciences, Islamabad.

DURATION OF STUDY Data collection was done for 6 months starting from September 2007 to March 2008.

SAMPLE SIZE Since reliable data for prevalence of open wounds requiring repeated dressing was not available I included patients under my care in the ward. These amounted to an average of 8 - 10 cases each month. Therefore, 120 cases were included in this study. 60 cases underwent Vacuum-Assisted Closure technique and 60 cases underwent wet to moist dressings

\subsection{Sampling Technique}

Double blinded Random sampling technique.

\subsection{Sample Selection}

Inclusion Criteria:

- Patients of both genders above the age of 13 years

- Open wounds on the trunk or limbs

Wounds inflicted by mechanical trauma-accidentally or surgically

- Wound involving skin and underlying soft tissues only

- Wound area ranging $10 \mathrm{~cm}^{2}$ to $100 \mathrm{~cm}^{2}$

Exclusion Criteria:

- Infection (urinary tract, pneumonia, wound infection)

- Albumin <3.0 gm/dl

- Renal, pulmonary, or other chronic disease requiring ongoing therapy for stabilization; uncontrolled diabetes mellitus, thyroid disease, or hypertension 
- Systemic steroids, other immunosuppressive therapy or anticoagulants

- Pregnant or breast-feeding patients

- The patient with osteomyelitis as determined by bone biopsy

- Patients whom we considered uncooperative or unsuitable candidates for participation in dressing changes

- Patients with malignant or neoplastic diseases in wound margin

Fistulas (rectal, stomal, or urethral fistulas to the wound)

STUDY DESIGN Quasi-Experimental study

\subsection{Data Collection}

Approval was obtained from the Hospital Ethics Committee. After a full explanation of the study, informed consent was obtained from each patient before enrolment. To avoid bias, double blinding was done. Patients with open wounds reporting to the general surgical specialty outpatient clinic and emergency were divided by randomization (lottery method) into two groups, one receiving VAC and the other WMD. To control confounding variables all patients seen for wound management were subjected to a rigorous nutritional assessment, with all receiving standard nutritional supplements, including zinc and multivitamin. All were placed on a pressure-relieving surface and underwent frequent examination of the wounds for healing and signs of infection. Wounds with necrotic tissue or debris had sharp debridement of the wound within 48 hours of the initiation of therapy. Antibiotic therapy was used in all patients according to culture reports.

The control group was treated with twice-daily dressings by conventional methods i.e. cleaning with normal saline, dressing the wound in saline-soaked gauze; whereas in the test group, topical negative pressure dressings were applied, and was assessed after intervals of 48 hours.

Technique of application:

A custom-made VAC system was employed. It comprised of a synthetic foam sheet, vacuum suction apparatus, and transparent semi-permeable adhesive membrane sheet. The procedure for applying it was as follows:

1) After necessary preparation, a tube drain with side holes was placed in the wound. The outer end of the tube was brought out subcutaneously a little away from the main wound.

2) The outside end of the drainage tube was connected to a suction apparatus to provide a negative pressure ranging from 20 to $200 \mathrm{mmHg}$.

3) A sterilized piece of foam, cut to the size of the wound and soaked in povidone iodine solution, was placed over the wound with the drainage tube underneath.

4) A semi-permeable, transparent adhesive sheath (Opsite) of appropriate size was then applied to the wound over the foam and secured in place so as to ensure water and air tight coverage of the wound.

5) The suction machine was then switched on. The vacuum so applied caused 
the foam to collapse giving a concave appearance to the wound surface.

6) The suction was maintained continuously. The fluid from the wound was absorbed by the foam and was removed from the wound bed by the suction.

7) After 48 hours, the dressing was removed, the wound was re-examined, washed with saline and the dressing was re-applied as before.

At the end of 48 hours wounds in both the groups were inspected after removal of the dressings. The wounds were compared based on the following parameters: rate of granulation tissue formation as percentage of the ulcer surface area, present dimensions and surface area of the ulcer. The procedure was being carried on for 15 days for both types of wounds. Follow up beyond the 15-day study period was done until complete wound closure was demonstrated for each patient. All patients were offered operative wound closure of any remaining open wounds (Figures 1-14).

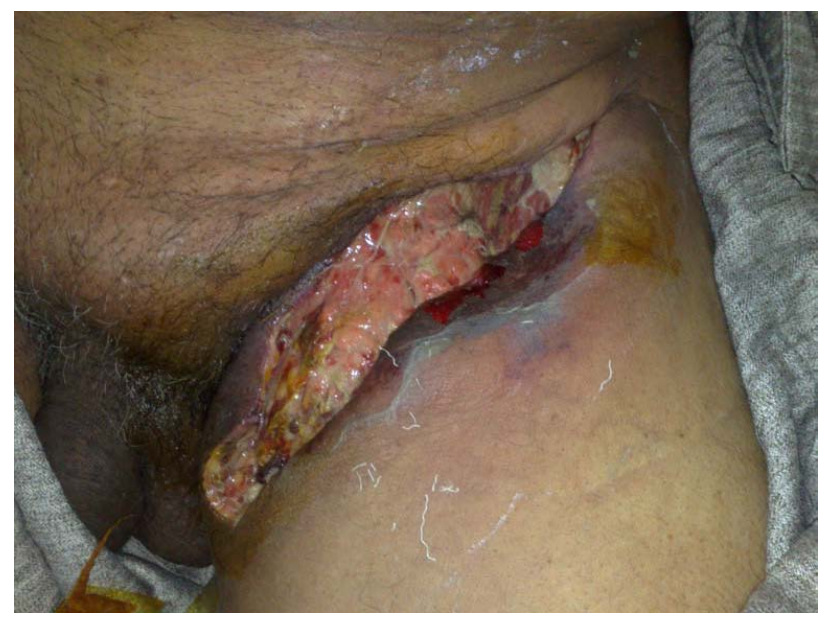

Figure 1. depicts a picture of an inguinal abscess after drainage and debridement prior to application of VAC dressing in our study.

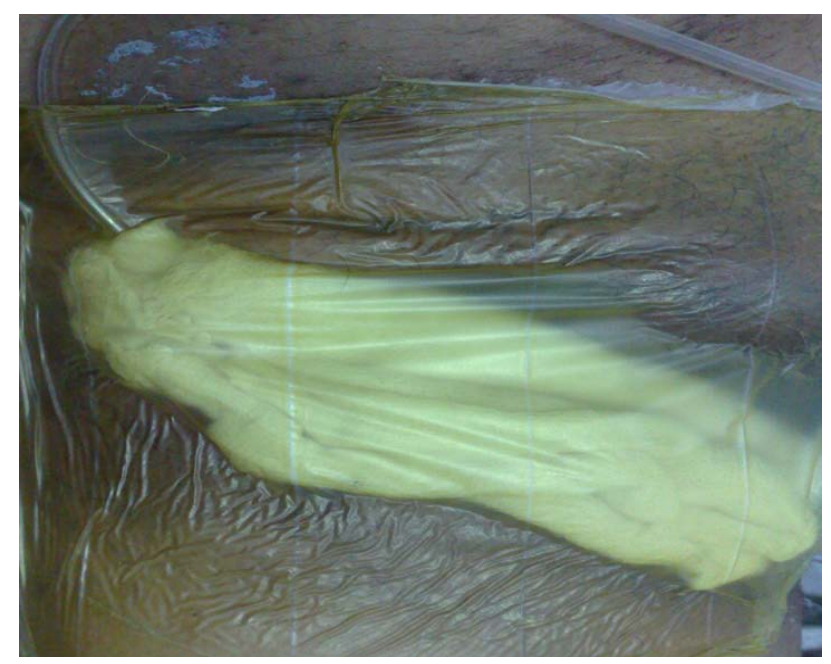

Figure 2. Depicts a picture that demonstrates VAC applied to the above wound. 


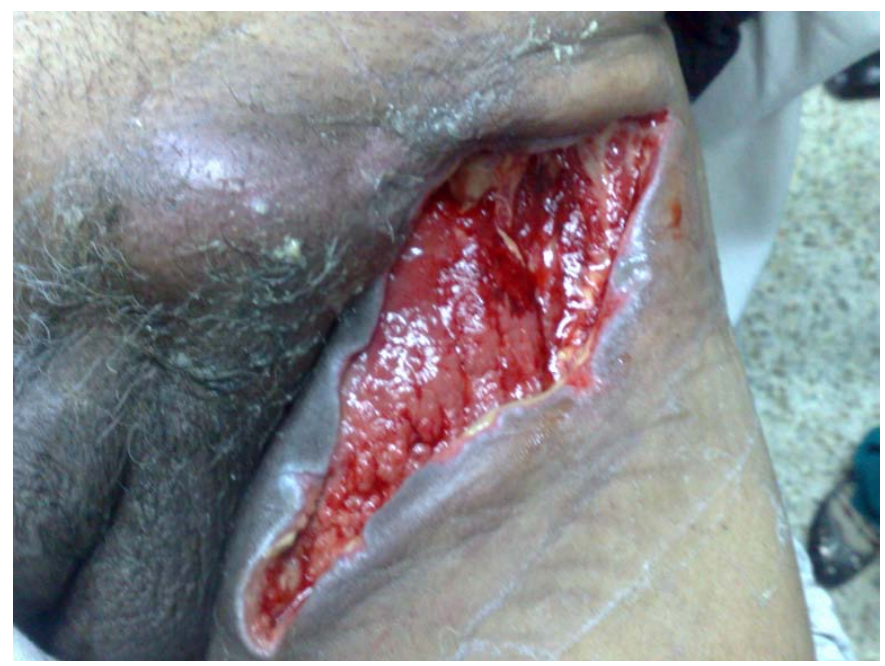

Figure 3. Shows a picture of the wound after VAC therapy showing granulation tissue, shrinkage of the wound and reduction of its depth.

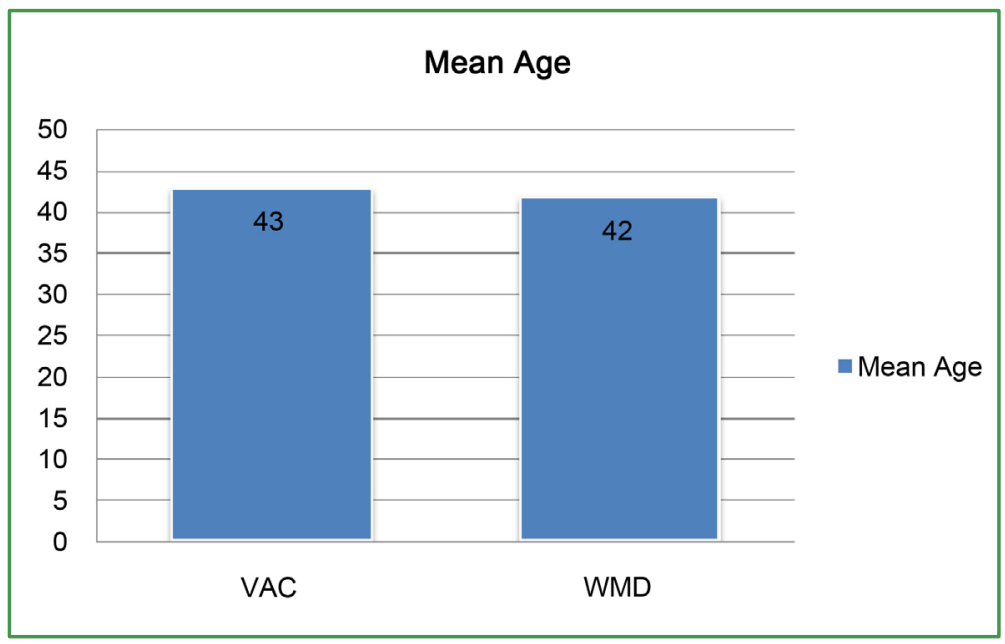

Figure 4. Shows the difference in age between both groups in the study.

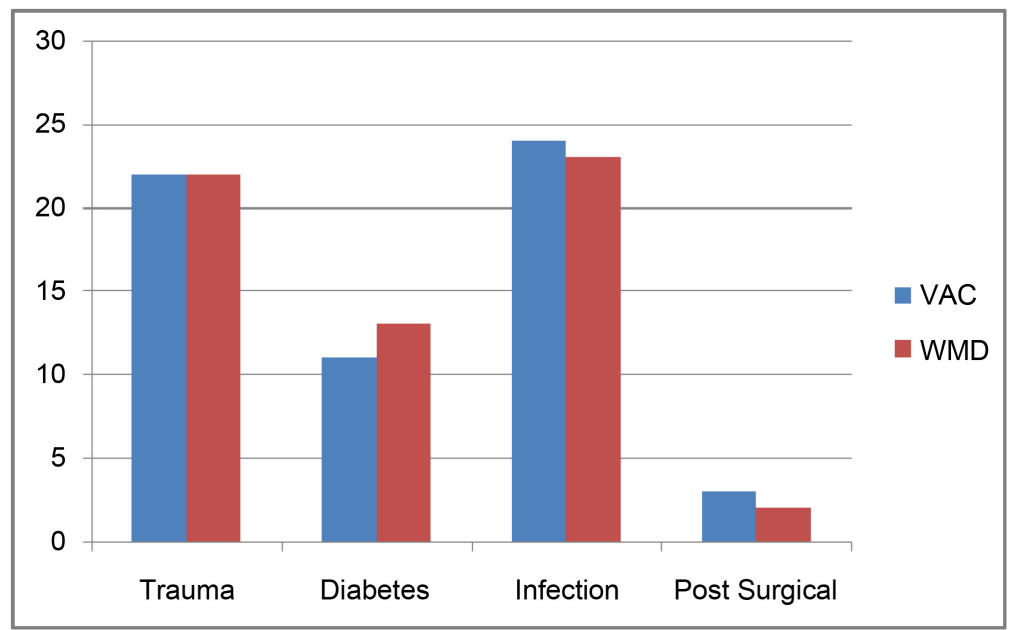

Figure 5. Depicts various types of wounds included in the study. 


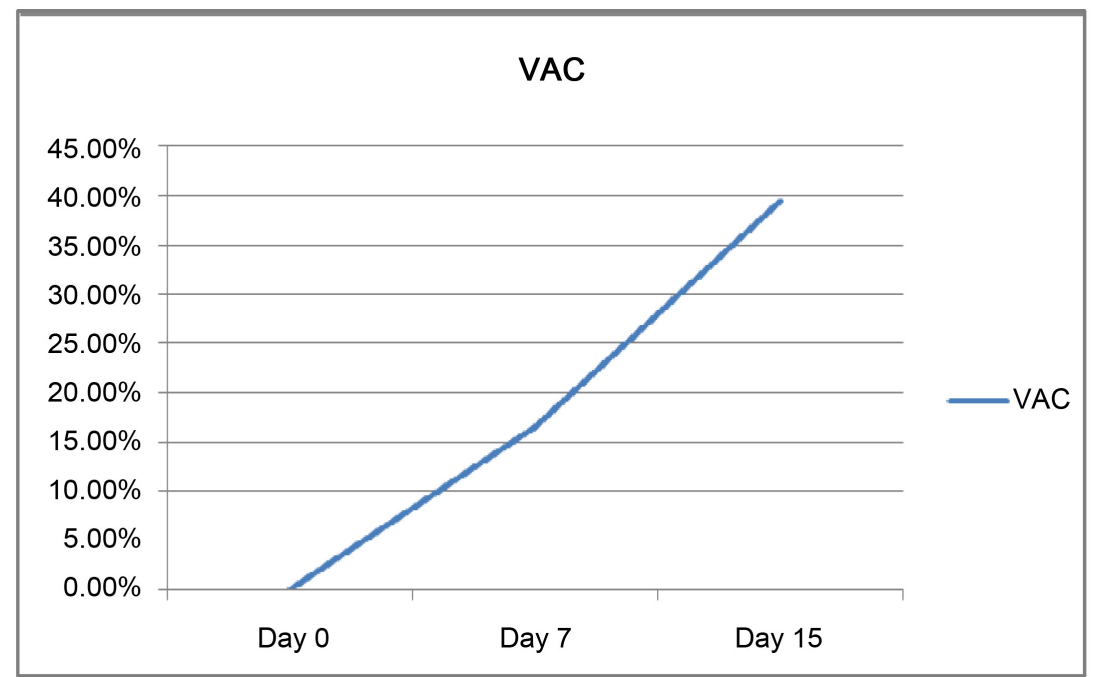

Figure 6 . Shows a reduction in surface area achieved by VAC over 15 days.

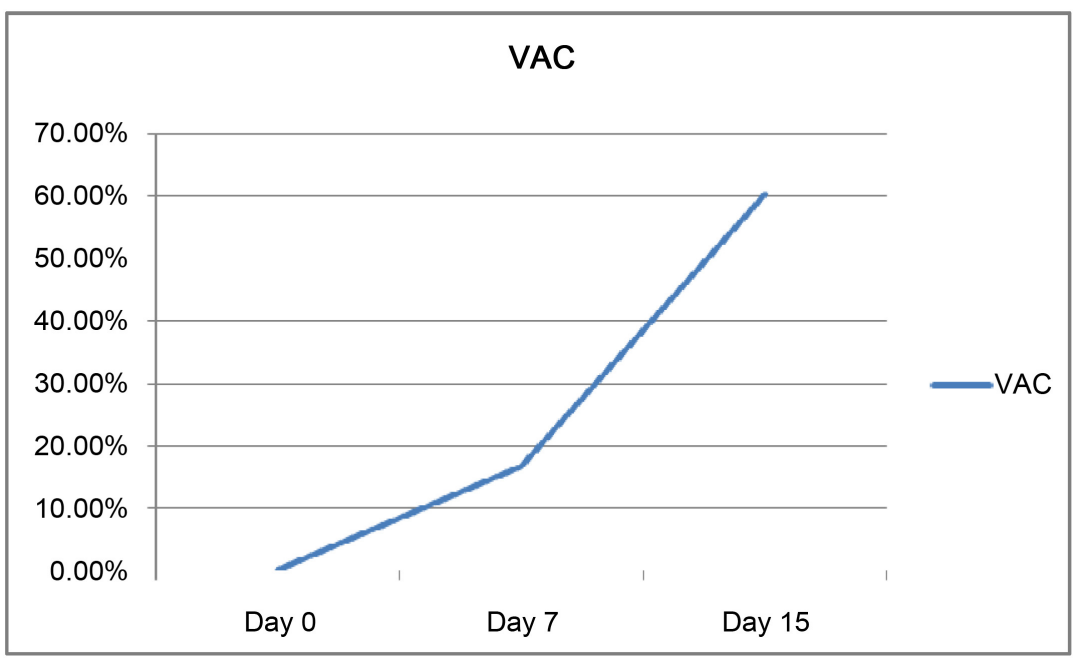

Figure 7. Shows a reduction in volume achieved by VAC over 15 days.

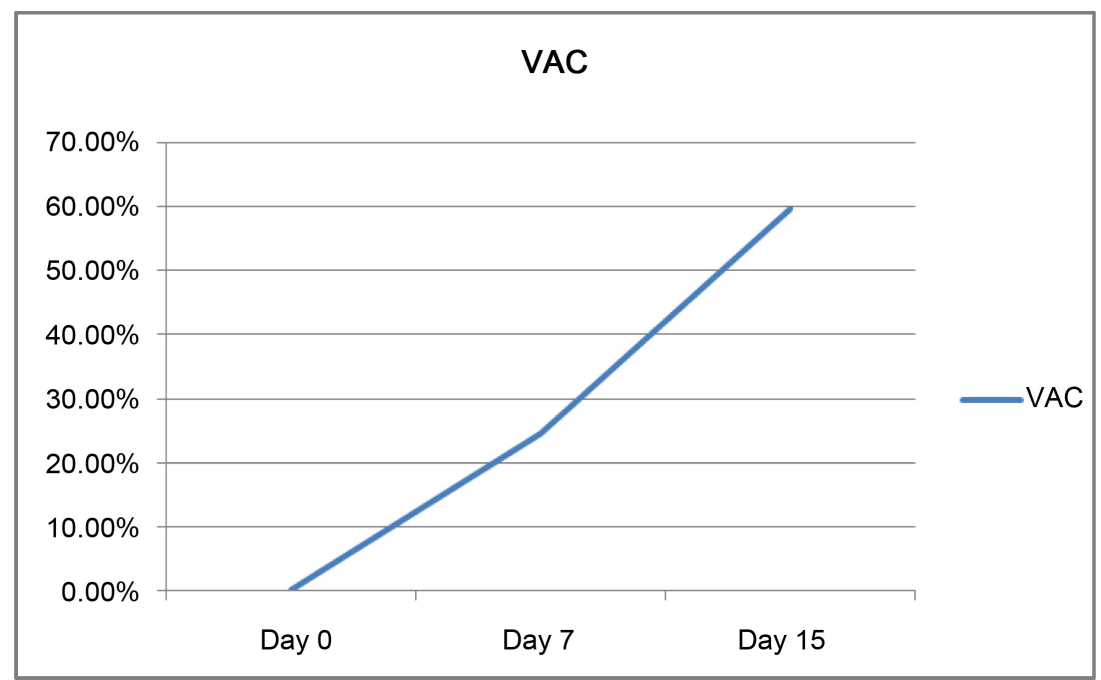

Figure 8. Estimates the percentage granulation achieved by VAC over 15 days. 


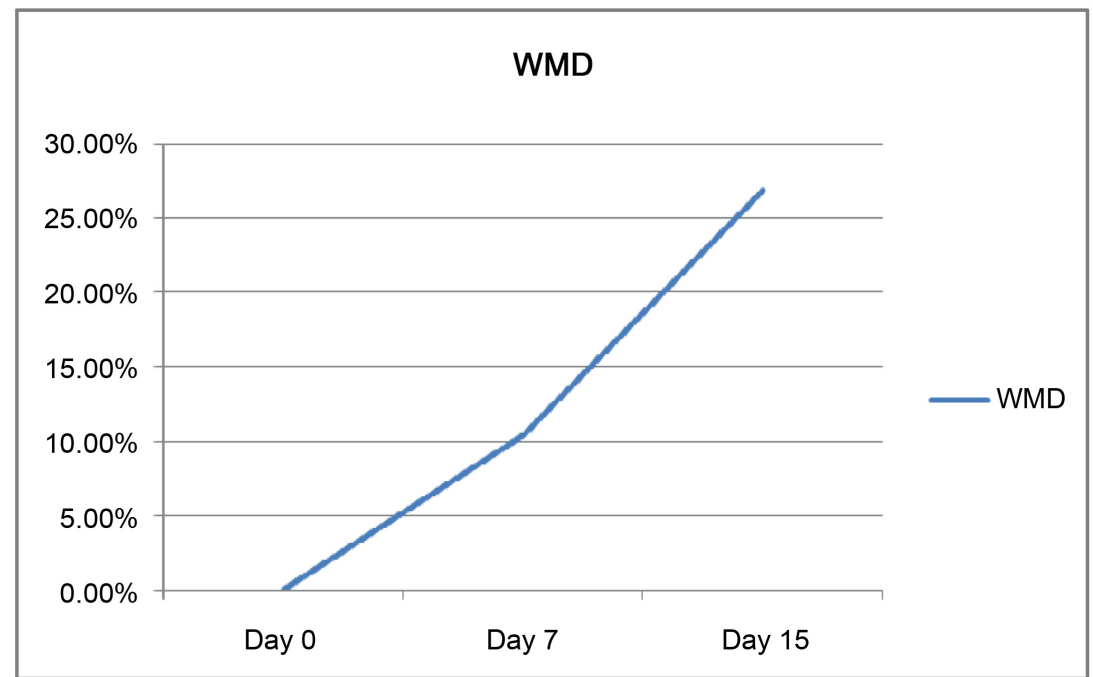

Figure 9. Shows the reduction in surface area achieved by WMD over 15 days.

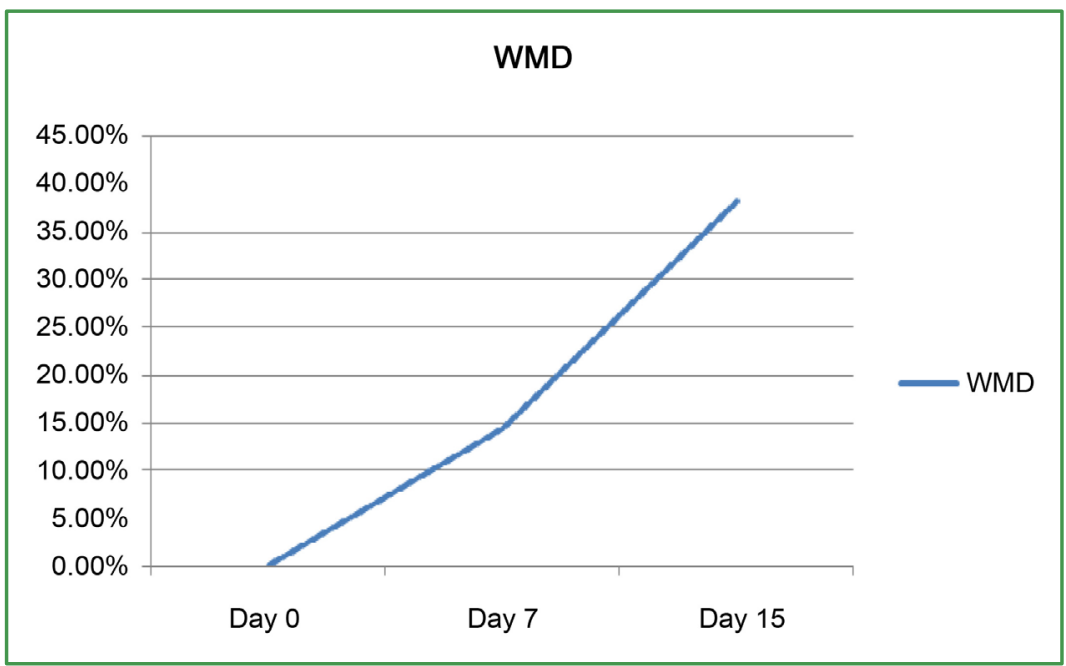

Figure 10. Depicts a reduction in volume achieved by WMD over 15 days.

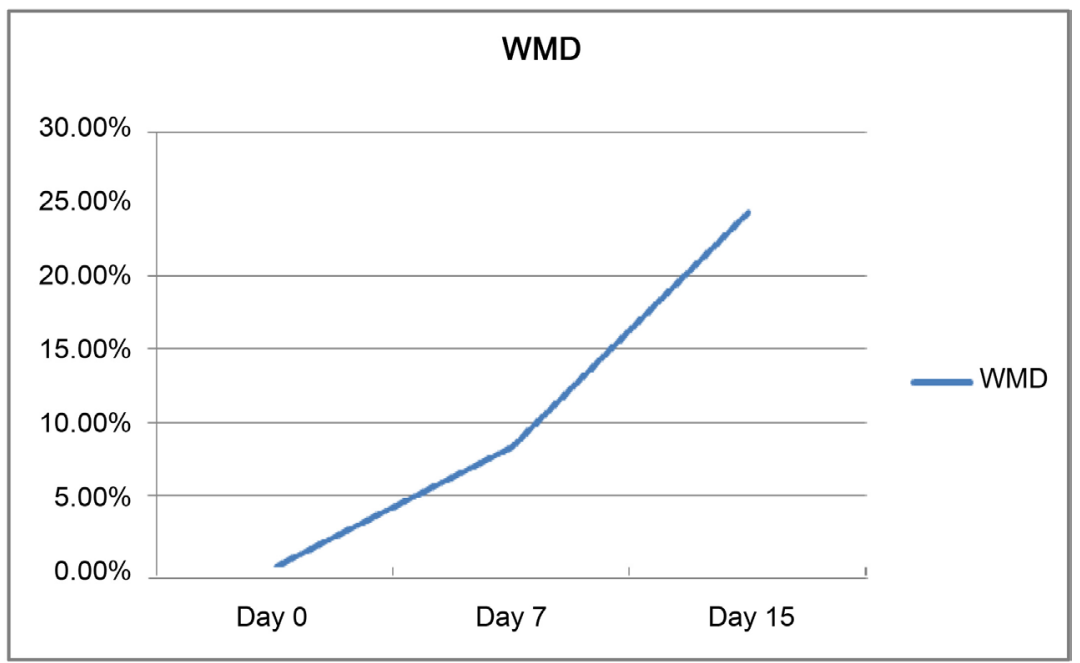

Figure 11. Shows the percentage granulation achieved by WMD over 15 days. 


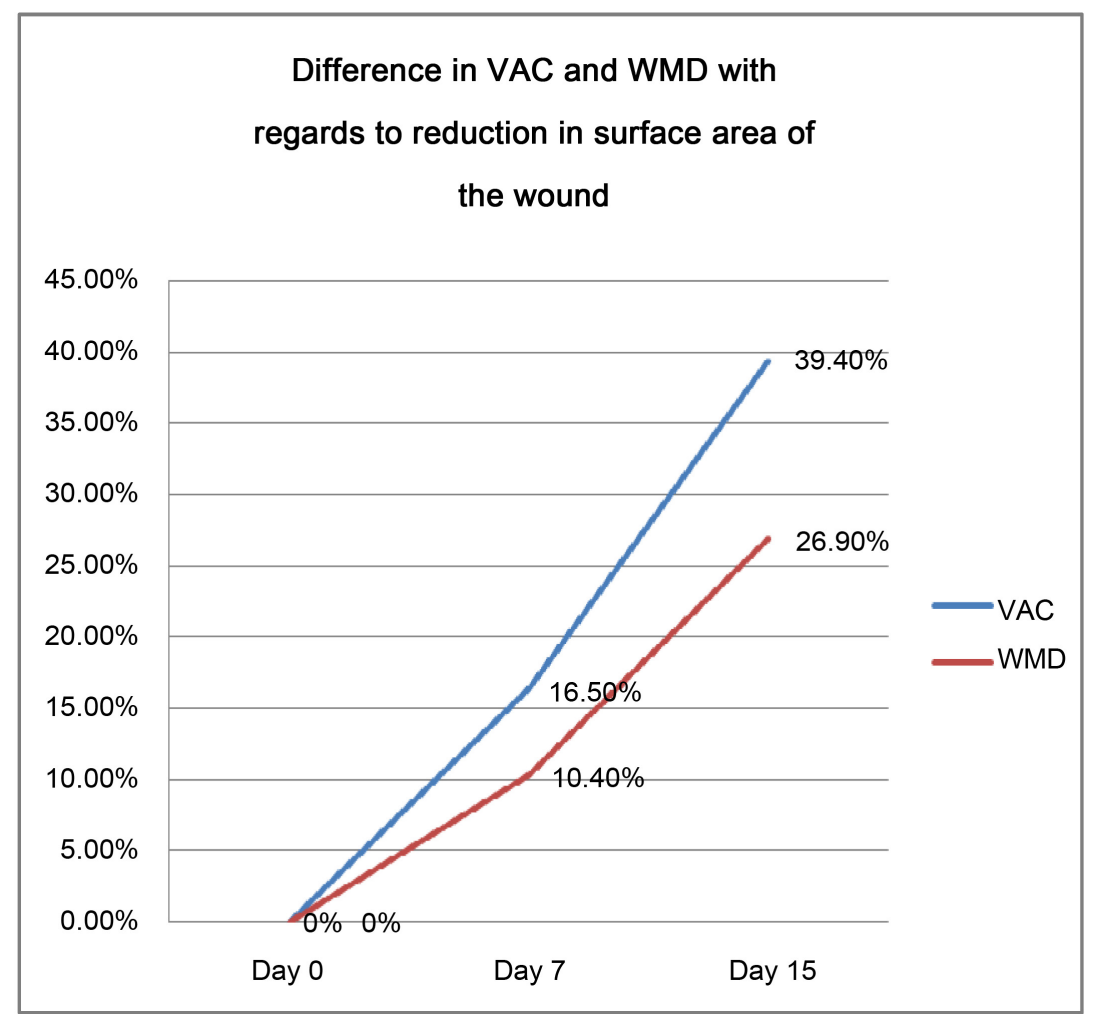

Figure 12. Shows the comparison of VAC and WMD in terms of reduction in surface area achieved over 15 days.

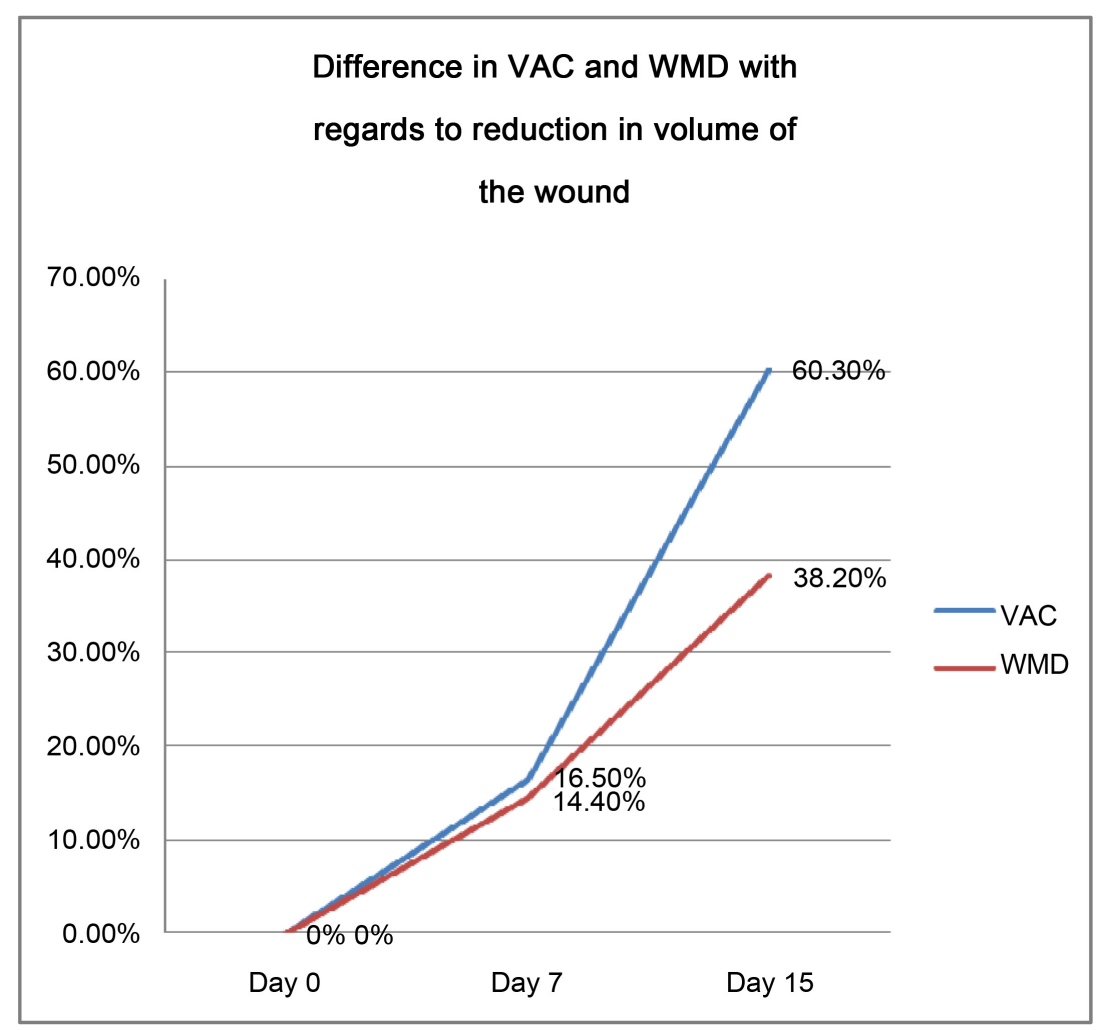

Figure 13. Shows the comparison of VAC and WMD in terms of reduction in volume achieved over 15 days. 


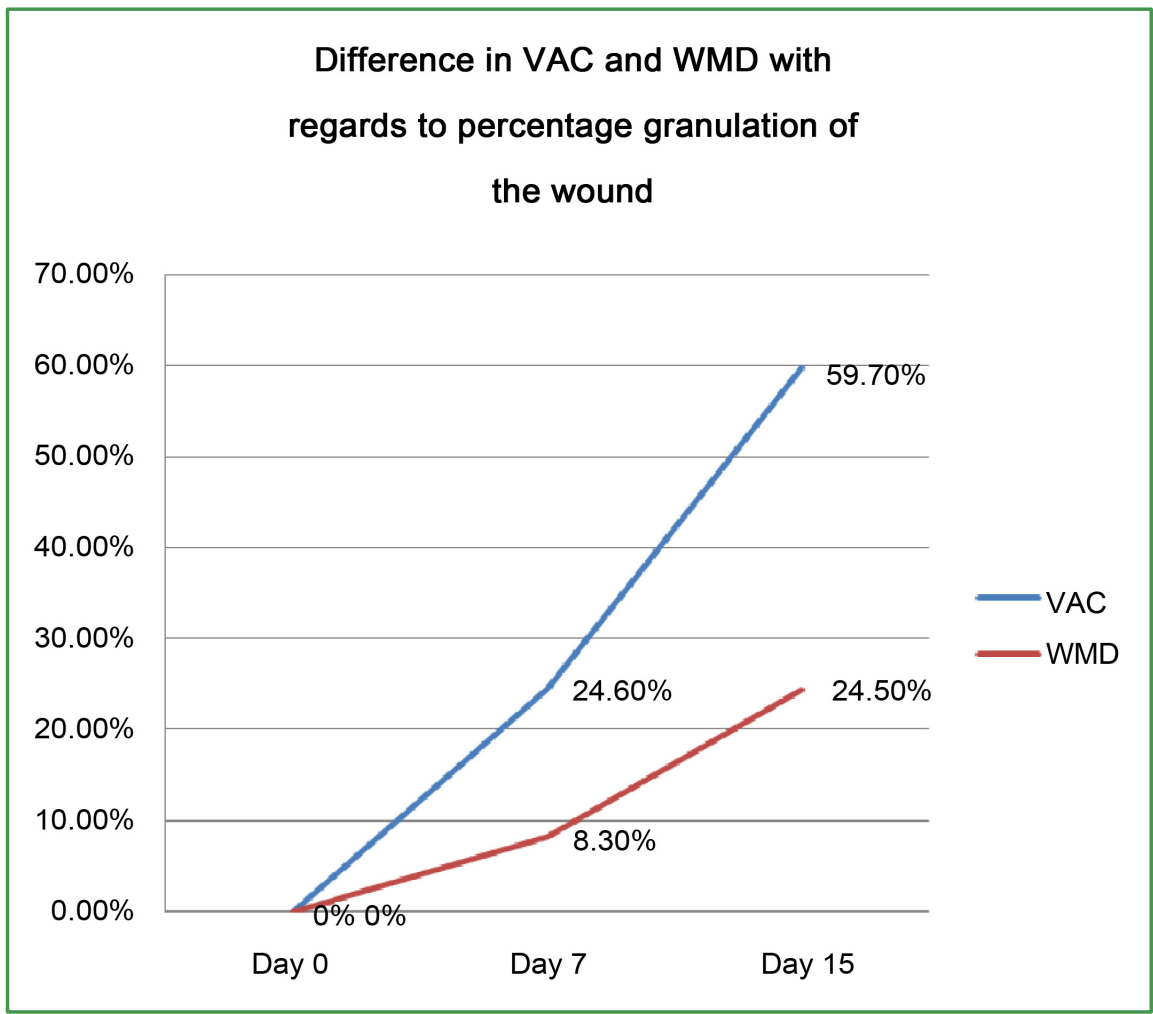

Figure 14. Shows the comparison of VAC and WMD in terms of percentage granulation achieved over 15 days.

\section{Results}

The total number of patients enrolled in the study from September 2007 to March 2008 is 120. All of these patients were suffering from open wounds which required regular dressing. Out of them 60 had their wounds managed with Vacuum Assisted Closure and the other 60 received conventional Wet to Moist dressing. The mean age of patients receiving VAC was 43 years. The youngest patient was 17 while the oldest was 86.40 patients (67 percent) were male while the rest of the 20 (33 percent) were female. 22 patients ( 37 percent) had wounds inflicted by various types of physical trauma, 11 patients (18 percent) had diabetes related ulcers, 24 patients (40 percent) developed wounds after different infections and 3 patients ( 5 percent) had open wounds following resection surgery. The mean age of patients receiving WMD was 42 years. The youngest patient was 9 while the oldest was 91.41 patients (68 percent) were male while the rest of the 19 ( 32 percent) were female. 22 patients ( 37 percent) had wounds inflicted by various types of physical trauma, 13 patients ( 22 percent) had diabetes-related ulcers, 23 patients ( 38 percent) developed wounds after different infections and 2 patients ( 3 percent) had open wounds following resection surgery.

When comparing the mean age of both the groups, no statistically significant difference was noted. ( $p$ value 0.771 ). Similarly, there was no significant difference between the aetiology of the ulcer between the two groups.

Table 4 Describes the demographical differences between both groups. 
Table 4. Demographical differences between both groups.

\begin{tabular}{ccc}
\hline Variable & VAC & WMD \\
\hline Mean Age & 43 & 42 \\
Male:Female ratio & $40: 20$ & $41: 19$ \\
Minimum age & 17 & 9 \\
Maximum age & 86 & 91 \\
Trauma related & $22(37 \%)$ & $22(37 \%)$ \\
Diabetes related & $11(18 \%)$ & $13(22 \%)$ \\
Infection related & $24(40 \%)$ & $23(38 \%)$ \\
Post-surgical & $3(5 \%)$ & $2(3 \%)$ \\
\hline
\end{tabular}

Patients enrolled in the first group were given VAC for their wounds. After a treatment period of 7 days, the patients in the group revealed a mean reduction in surface area of $16.5 \%$ and at the end of the 15-day study period the mean reduction in surface area of the wound was $39.4 \%$. The mean reduction in volume of the wound in this group at 7 days was $16.5 \%$ of the initial volume while the mean reduction in volume at 15 days was $60.3 \%$. Similar results were seen with regard to granulation of the wound. At 7 days after the start of the treatment a mean of $24.6 \%$ of the wound area showed granulation tissue formation and at 15 days a mean of $59.7 \%$ of the wound surface area had granulation tissue formation. Paired sample student $t$-test was applied to determine the significance of reduction in the wound size with this type of treatment in regard to all the above-mentioned criteria of wound healing. Mean reduction in surface area at the start of treatment was compared with mean reduction in surface area at the end of 15 days by applying paired sample student t-test and the difference between them was found to be significant statistically ( $p$ value $<0.001$ ). Mean reduction in volume of the wound at the start of treatment was compared with mean reduction in volume at the end of 15 days by applying paired sample student $\mathrm{t}$-test and the difference between them was also found to be significant statistically ( $\mathrm{p}$ value $<0.001$ ) Mean percentage of granulating wound at the start of treatment was compared with mean percentage of granulating wound at the end of 15 days by applying paired sample student $t$-test and the difference between them was found to be highly significant statistically ( $\mathrm{p}$ value $<0.001$ ).

Patients who made up the second group were given WMD for their wounds. After a treatment period of 7 days the patients in the group revealed a mean reduction in surface area of $10.4 \%$ and at the end of the 15 day study period the mean reduction in surface area of the wound was $26.9 \%$. The mean reduction in volume of the wound in this group at 7 days was $14.4 \%$ of the initial volume while the mean reduction in volume at 15 days was $38.2 \%$. Similar results were seen with regard to granulation of the wound. At 7 days after the start of the treatment a mean of $8.3 \%$ of the wound area showed granulation tissue formation and at 15 days a mean of $24.5 \%$ of the wound surface area had granulation tissue formation. Paired sample student $\mathrm{t}$-test was applied to determine the sig- 
nificance of reduction in the wound size with this dressing in regard to all the above-mentioned criteria of wound healing. Mean reduction in surface area at the start of treatment was compared with mean reduction in surface area at the end of 15 days by applying paired sample student t-test and the difference between them was found to be significant statistically ( $p$ value $<0.001$ ). Mean reduction in volume of the wound at the start of treatment was compared with mean reduction in volume at the end of 15 days by applying paired sample student $t$-test and the difference between them was also found to be significant statistically ( $\mathrm{p}$ value $<0.001$ ).

Mean percentage of granulating wound at the start of treatment was compared with mean percentage of granulating wound at the end of 15 days by applying paired sample student $\mathrm{t}$-test and the difference between them was found to be highly significant statistically ( $\mathrm{p}$ value $<0.001$ ).

Both types of dressing were compared with each other in relation to the pre-determined parameters of healing. With regard to reduction in surface area of the wound at both day 7 and day 15 of the treatment the statistical difference between both types of treatment was significant, with VAC displaying better results. (p value 0.01 at day 7 and p-value $<0.001$ at day 15 ) Considering the reduction in volume at day 7 there was no statistical difference between both dressings. ( $\mathrm{p}$ value 0.386 ). However, at day $15 \mathrm{VAC}$ proved to be the better of the two with highly significant reduction in volume. ( $\mathrm{p}$ value $<0.001$ ) Lastly, analysing the mean percentage granulation with time of both the groups VAC again proved to be superior with highly significant statistical difference. ( $\mathrm{p}$ value $<$ 0.001 ) at both day 7 and at day 15. There were no significant adverse effects noted with both forms of treatment.

\section{Discussion}

In the developed world, billions of dollars are spent on wound care specially treatment of chronic wounds. A wide array of methods and devices has been developed in this situation to cope with the burden. Ranging from surgical debridement and wound closure to novel forms of dressings much has been done to bolster our armamentarium to fight this war. Most surgical wounds are closed primarily, but some are allowed to heal by secondary intention. This usually involves repeated packing and dressing of the raw wound surfaces. Although the long-term care of such wounds has been delegated to the care of nurses in the community or out-patient setting, the initial wound dressing or cavity packing is done by the surgeon in the operating theatre. Many surgeons are unaware of the growth of the discipline of wound care, and still use traditional soaked gauze for dressing and packing open surgical wounds and cavities [55]. Amidst this situation a relatively new and advanced technique has been developed known as the VAC technique of wound closure based on Negative Pressure Wound Therapy. The vacuum assisted closure (VAC) therapy was first reported in the 1990s. Pioneering work was done by Argenta, et al. who reported favorable results in 
wound healing utilizing the VAC technique [4] [5]. In this day and age, truly unique discoveries are unusual. Almost every "new" treatment is, in fact, a modification of a previously described technique. This is also true for wound treatments. The negative pressure dressing itself is a very useful and ancient method stemming from a historical continuum [65]. At this juncture it is pertinent to be shed some light on historical background and evolution of this treatment. The negative pressure dressing has been used since the 19th century for wound care purposes. Initially, a device to create negative pressure was used to allow difficult thoracic operations while avoiding collapse of the lungs. Around 1905 a new technique was born. The patient's head protruded outside a negative pressure chamber while the patient's body, together with the surgeon, was inside the chamber. The machine was then miniaturized by the surgeons during the World War I. Dr. Sauerbruch, born in 1875 in Barnum, Germany, invented a portable bell which, put over the chest, isolated the thorax and the surgeons' hands only. Here is the description of its first use according to his memories [66] the most difficult part was to supply this glass bell with an air absorbing pump (...). We prolonged our evening by calculating everything and in the daylights both boys went their ways. They first visited the glassworker, the second looked for rubber and valves. (...) At the moment that I could slide my hands into the drum, manipulate freely my instruments inside, without air leak from outside, the preliminary experimental conditions seemed to be satisfied. Our first victim was Cesar, a very small hairy stray dog, who loved one of the lab boys. (...) Several clinical notes from the same author in his autobiography describe further refinements to the bells allowing the treatment of infected wounds, especially on legs. In more recent times, the technique was used by Russian surgeons during the 1970s. The principle was to apply a transparent flexible top under which a vacuum was created mostly by wall suction. This bell mechanism was adapted by Blue Sky Medical in 2003 as the "Miller DermiVex" "procedure. In 1986, Kostiuchenok et al. demonstrated in a controlled study on 90 persons, the superiority of surgical debridement of infected wounds after negative pressure dressing compared with surgical debridement alone. Davydov et al. in 1986 demonstrated the use of the negative pressure dressing for purulent lactation mastitis on a series of 97 patients. In 1989, Chariker et al. published a negative pressure dressing method connecting wall suction via a silicon drain, on simple dressing gauze and a self-adherent semipermeable membrane covering the wound. Again, this procedure was bought by Blue Sky Medical in 2003 under the name of "Chariker-Jeter technique." The worldwide acceptance of the method is due to work by Morykvas et al., who in 1987 developed a system, subsequently commercialized by $\mathrm{KCI}$, including a polyurethane sponge and distributing negative pressure by intermittence or continuous suction through a machine. Their approach involved repeating animal studies, especially on skin donor sites in pigs, and then reducing a number of clinical publications based upon this research. The exact mechanism by which VAC produces its effects are diverse and have 
been alluded to previously. Here I would like to elaborate on them. Oedema in wounds increases capillary stasis, which in turn produces capillary thrombosis and thereby reduces microcirculation. The rationale behind the use of vacuum dressing was that negative pressure spreading along the surface of an open wound removes oedema fluid and tissue debris to decrease the blood perfusion. The reduction of oedema combined with the application of negative pressure forces enhances the formation of granulation tissue. Chen et al. based their study on the perfusion of tissues under the effect of negative suction. They believed that by increasing capillary calibre and blood volume and by stimulating angiogenesis, VAC could improve blood circulation in wounds. They concluded that by narrowing endothelial spaces and by restoring the integrity of capillary basement membranes, VAC could decrease the permeability of blood vessels and wound oedema [67]. Apart from being superior to WMD, VAC is believed to be better than other semi-occlusive dressings at the molecular level in acute wounds. Kloeters et al. revealed that semi-occluded wounds demonstrated decreased epidermal thickness and cellularity and less mitotic epidermal. Associated dermal cellularity was similarly attenuated by semi-occlusion. Finally, levels of proinflammatory cytokines IL-1-alpha and TNF-alpha were significantly decreased on postoperative day 3 at the transcriptional level. Semi-occlusive wound treatments significantly decrease epidermal thickness, cellularity, mitotic activity and dermal cellularity as well as transcriptional levels of important epidermal mediators of inflammation in a rat incisional wound model [68]. Over the past two decades, topical negative pressure (TNP) wound therapy has gained wide acceptance as a genuine strategy in the treatment algorithm for a wide variety of acute and chronic wounds [69]. While all the studies done on VAC so far indicate that the NPWT therapy is more effective than conventional dressings there is a strong need for larger trials to assess NPWT therapy in wound care with different groups of patients and in relation to different clinical objectives and parameters. Although case reports and retrospective studies have demonstrated enhanced wound healing in acute/traumatic wounds, chronic wounds, infected wounds, wounds secondary to diabetes mellitus, sternal wounds and lower limb wounds, there are very few randomised controlled trials, with unclear results [70]. We have endeavoured to the best of our abilities to contribute to re-enforcing what other researchers have already attempted to prove. This study focuses more on the common etiological factors like diabetes trauma infected wounds and post-surgical wounds which presented in the surgical outpatient's department as well as the emergency department. Although VAC is marketed as V.A.C. Therapy by $\mathrm{KCl}$, San Antonio, Texas, many innovations and adaptations have been made along the path of its evolution. These include modifications in its design to make it available to populations which do not have the resources to afford the patented system which has to be imported at great cost from abroad. Perez et al. conducted a clinical randomized trial to determine whether a simple homemade wound vacuum-dressing system is a feasible alternative to the use of 
conventional saline-soaked gauze dressings for the treatment of complex wounds in a resource-poor hospital [71]. They concluded that the homemade system should be considered in underdeveloped countries to provide modern management for complex wounds because healing is significantly faster compared with conventional wound care. Although this is more costly than the conventional approach, it is probably affordable for most resource-poor hospitals. We have also based this study on the basis that a cheaper and more readily available system should be employed to provide patients at our hospital with the same advanced wound therapy which hospital in developed countries offer. Further, there was a dearth of evidence in local literature regarding VAC therapy. Published international studies have employed the patented VAC Therapy $(\mathrm{KCl}$, San Antonio, Texas) to conduct their trials. However, this study has attempted to use a modified system on a reasonably large sample size compared to Perez et al. After analysis my results reveal that even the modified VAC is statistically superior to wet to moist dressing. During the past several years, vacuum-assisted closure (VAC) system has been increasingly used in the treatment of gastrointestinal cutaneous fistulas, particularly those associated with open abdomen [72]. These patients, who have exposed bowel, may develop an additional fistula that may require surgery. In a recent article from an intestinal-failure unit in the United Kingdom, Rao et al. reported on a series of 29 patients treated with VAC [6], who developed new gastrointestinal cutaneous fistulas. Four of these 6 patients died. The report of Rao et al., suggest the possibility that the use of the VAC system in patients with exposed bowel and an open abdomen may be associated with subsequent fistula development. Although the numbers are small, it also raises the question that development of a fistula in a patient treated with VAC may result in higher mortality. Bee et al. reported similar results when they evaluated the use of polyglactin 910 mesh and VAC for abdominal wall closure. They found out that although both are useful methods for abdominal coverage, and are equally likely to produce delayed primary closure. But both techniques resulted in an unacceptably high rate of fistula formation. The fistula rate for VAC is most likely due to continued bowel manipulation with VAC changes with a feeding tube in place. Apart from that neither method precludes secondary abdominal wall reconstruction as definitive treatment [73]. Keeping the above fact in mind we excluded patients with gastrointestinal cutaneous fistulas from our study. This has been a major cause of the high percentage of success we observed in wound healing with both modalities. Negative pressure wound therapy also known as vacuum-assisted closure has become an increasingly important part of wound management [74]. Over the last decade, numerous uses for this method of wound management have been reported, ranging from acute and chronic wounds, to closure of open sternal and abdominal wounds, to assistance with skin grafts. One major area where it has found particular importance is in chronic wounds. Foot ulcers are a common complication in patients with diabetes. The aetiology of $11 \%$ to $13 \%$ of our pa- 
tients was diabetes-related chronic ulcers. The healing rates achieved by both VAC and WMD were significant at 15 days of treatment. However, healings rates were better with VAC therapy when compared with WMD ( $\mathrm{p}$ value < 0.001) Negative pressure wound therapy (NPWT) is a wound care therapy that is being increasingly used in the management of foot ulcers. Topical negative pressure (TNP) is a mode of therapy used to encourage wound healing [75]. It can be used as a primary treatment for chronic/complex wounds or as an adjunct to surgery. Blume et al. conducted a randomized controlled trial in which the primary endpoint was to determine the effect of NPWT on incidence of complete ulcer closure. The results demonstrate that NPWT is effective for treating diabetic foot ulcers and has a positive effect on outcomes such as secondary amputations. As for occurrence of infections, there was no statistical significance found between specific infection types and treatment type [76]. Fife et al. evaluated the safety of negative pressure wound therapy using the vacuum-assisted closure (V.A.C. ${ }^{\bullet}$ ) Therapy System (KCI, San Antonio, TX) in diabetic foot ulcers among wound centre outpatients. They defined events that could represent complications or adverse events as a result of treatment with the VAC, including symptoms of infection, pain, bleeding and peri-wound skin breakdown. The frequency of these effects among VAC patients with DFUs was compared with those among similar non-VAC patients. This project prospectively queried data collected during routine clinical care from 16 outpatient wound centres using the Intellicure electronic medical record system. The electronic records were de-identified according to Health Insurance Portability and Accountability Act (HIPAA) requirements and pooled to create a data repository dedicated to research (the Intellicure Research Consortium). Analysis was performed on 1331 DFUs representing 16438 outpatient visits. A total of 1299 non V.A.C. and 72 V.A.C. DFUs were available for analysis. Their study neither revealed any statistical difference between the adverse effects of VAC versus non-VAC patients nor that the VAC exerted a protective effect. They concluded that the VAC is safe in outpatient use [77]. Ferreira et al. also published their experience suggesting that negative pressure therapy may have an important role in wound bed preparation and as part of the treatment for wounds in the lower limbs of diabetic patients [78]. Fasciotomy wounds can be a major contributor to length of stay for patients as well as a difficult reconstructive challenge. Once the compartment pressure has been relieved and stabilized, the wound should be closed as quickly and early as possible to avoid later complications. Skin grafting can lead to morbidity and scarring at both the donor and fasciotomy site. Primary closure results in a more functional and aesthetic outcome with less morbidity for the patient, but can often be difficult to achieve secondary to oedema, skin retraction, and skin edge necrosis. Zannis et al. examined fasciotomy wound outcomes, including time to definitive closure, comparing traditional wet-to-dry dressings, and the vacuum-assisted closure (VAC) device. In comparing all wounds, there was a statistically significant higher rate of primary 
closure using the VAC versus traditional wet-to-dry dressings ( $\mathrm{p}$ value $<0.05$ for lower extremities and $\mathrm{p}$ value $<0.03$ for upper extremities). The time to primary closure of wounds was shorter in the VAC. group in comparison with the non-VAC group. This study has shown that the use of the VAC for fasciotomy wound closure results in a higher rate of primary closure versus traditional wet-to-dry dressings. In addition, the time to primary closure of wounds or time to skin grafting is shorter when the VAC was employed. The VAC used in the described settings decreases hospitalization time, allows for earlier rehabilitation, and ultimately leads to increased patient satisfaction [79]. The patients in our study with acute wounds either secondary to trauma or to surgery showed statistically better results with VAC therapy compared to WMD ( $\mathrm{p}$ value $<0.001$ ).

Comparable results were obtained by Cresti et al. They studied the effects of $\mathrm{VAC}$ on wounds after abdominoperineal resection for rectal carcinoma. Primary closure of the perineum with drainage after abdominoperineal excision of the rectum for carcinoma, is widely accepted. However, hematoma, perineal abscess and re-operation are significantly more frequent after primary closure than after packing of the perineal cavity. Those complications are frequently related to the patients' clinical antecedent i.e. radiotherapy, diabetes, smoking. The results showed favourable outcome of the association of omentoplasty and VAC system. Those findings led them to favour VAC system in the case of pelvic exenteration associated with high risk of infection [80]. Le Franc et al. of the University Hospital Centre of Nantes (acute care), investigated a cost-effectiveness assessment of negative pressure wound therapy, in comparison with moist wound therapy, in the surgical preparation of cutaneous defects requiring reconstructive surgery. This retrospective study was realized after data collection from patient files with hospitalization for the management of open-leg fractures with a view to reconstructive surgery by graft or flap. Effectiveness criteria, after debridement and NWPT initiation, was the time period required for preparing the wound for definitive reconstructive surgery closure by flap or graft. The research revealed that wound preparation time is significantly shorter for patients treated with negative pressure therapy ( $\mathrm{p}$ value $=0.026$ ) and is equal to 20 days less on average for time period required for preparing the wound for reconstructive surgery. Hospitalization costs is very significantly lower for patients being treated with VAC $(p=0.02)$ [81]. de Leon et al. conducted a similar study to evaluate the cost-effectiveness of negative pressure wound therapy using reticulated open-cell foam in patients with complex wounds in a long-term acute care setting (LTAC). These patients are routinely discharged to LTAC hospitals with the goal of accelerating wound healing and timely transfer to a lower acuity care setting and are usually affected with serious co-morbidities and deep, complex wounds with exposed anatomical structures, which require extended care (stay > 25 days). Postsurgical LTAC patients who were treated by VAC had a more accelerated rate of wound closure, compared with patients treated with advanced moist wound-healing therapy. These results suggest that, for this patient group, VAC 
may be more clinically effective in reducing wound volume, compared with advanced moist wound healing. Furthermore, the lower cost per cubic centimetre volume reduction suggests that VAC produces a more favourable cost-effective solution. Therefore, it is important when developing a wound-healing strategy that cost decisions be based on overall cost and not individual product cost when using advanced technology as part of the overall treatment plan. This study served as a basis for further work in cost-benefit analysis when considering evidence-based outcomes in wound care [82]. Flaps are currently the predominant method of reconstruction for irradiated wounds. The usefulness of split-thickness skin grafts (STSG) in this setting remains controversial. A study was planned with objective to examine the outcomes of STSGs in conjunction with VAC therapy used in the treatment of irradiated extremity wounds. Senchenkov et al. concluded that although flap coverage is an established treatment for radiated wounds, STSG in conjunction with liberal utilization of VAC therapy is an alternative for selected patients where acceptable soft tissue bed is preserved. Healing of the preoperatively radiated wounds can be achieved in the vast majority of such patients with minimal need for additional reconstructive operations [83]. Llanos et al. also corroborated the previous results and said that the use of VAC significantly diminishes the loss of STSG area, as well as shortens the days of hospital stay. Therefore, it should be routinely used for these kinds of procedures [84]. Moisidis et al. in their study concluded that topical negative pressure significantly improved the qualitative appearance of split-thickness skin grafts as compared with standard bolster dressings [85]. Chest wall reconstruction remains one of the most challenging areas of Plastic and Reconstructive Surgery. Khan et al. published their 4-year experience with chest wall reconstruction. They reviewed 62 patients who had chest wall reconstruction from 2001 to 2004. Indications included; defects secondary to congenital deformity correction, post-neoplastic reconstructions, post-burn defects and sternotomy wounds. Procedures performed included direct closure after debridement, vacuum-assisted closure with and without skin grafting, pectoralis major flap, rectus abdominis flap, omental flap and free flaps including latissimusdorsi flap. The average hospital stay was 13 days. Uneventful recovery was seen in 50 patients. Minor complications were seen in 12 patients whereas major complications were not seen in any patient. They concluded that chest wall reconstruction can be performed with satisfactory outcome provided that reconstruction ladder is followed [86]. Our study included patients with de-gloving injuries and skin defects requiring reconstruction to achieve good cosmetic results. VAC revealed comparatively better results than WMD in preparing wounds to be referred to the Plastic surgery department after treatment for their primary injury with regards to time to decrease in surface and volume of the wound. Stannard et al. suggested that patients treated with NPWT were only one-fifth as likely to have an infection compared with patients randomized to the control group. NPWT represents a promising new therapy for severe open fractures after 
high-energy trauma [87]. Stannard et al. in another publication described the use of VAC on many complex traumatic wounds. Potential mechanisms of action include angiogenesis, increased blood flow, and decreased interstitial fluid. This randomized study demonstrated decreased drainage and improved wound healing following both hematomas and severe fractures [88] [89]. Up to $40 \%$ of patients in our study had trauma-related wounds. They ranged from minor lacerations to extensive bomb blast wounds. The mean reduction in surface area over a 15-day period of these wounds treated with VAC was very significantly greater than wounds treated with WMD. Braakenburg et al. in their trail of 24 patients with chronic wounds concluded that with vacuum-assisted closure therapy, wound healing is at least as fast as with modern wound dressings. Especially cardiovascular and diabetic patients benefit from this therapy. The total costs of vacuum-assisted closure are comparable to those of modern wound dressings, but the advantage is its comfort for patients and nursing staff [90]. Vuerstaek et al. concluded in their study on the effect VAC on chronic leg ulcer that VAC therapy should be considered as the treatment of choice for chronic leg ulcers owing to its significant advantages in the time to complete healing and wound bed preparation time compared with conventional wound care. Particularly during the preparation stage, VAC therapy appears to be superior to conventional wound care techniques [91]. We included some patients from our study from the paediatric age group. However, there were no adverse effects seen by doing so and they showed comparable and favourable results as the other participants. These views were shared by Caniano et al. who concluded that negative pressure therapy offers a safe, cost-effective alternative to traditional complex wound care in children. Its advantages are less frequent dressing changes, outpatient management, resumption of daily activities including return to school, and a high degree of patient tolerance [92]. I would like to mention some case reports with excellent results obtained by the use of VAC. Ahmad et al. described the case of a 36 years old male who presented after 3 days of an accident. He had multiple injuries and a dirty infected wound on the dorsum of the right foot with the exposed tendons. After initial surgical debridement, VAC was applied which was changed after every 48 hours. The VAC device consisted of a double layer of half inch-thick open cell foam into which was embedded an evacuation tube of 16 or $18 \mathrm{Fr}$. The tube was connected to a $5 \mathrm{ml}$ syringe. The tube from collection container of vacuum pump was placed inside the syringe. The foam was soaked with Pyodine ${ }^{\oplus}$ and trimmed and fitted according to the dimensions of the wound, and was applied in direct contact with the base of the wound. Pre-op drapes (Opsite ${ }^{\oplus}$ ) were used extending 3 - $5 \mathrm{~cm}$ beyond the margins of the wound to create an airtight seal. For the first 24 hours, $125-150 \mathrm{mmHg}$ of continuous negative pressure was applied and then shifted to intermittent pressure cycles of 20 minutes ON and 5 minutes OFF for the next 24 hours. After 48 hours of VAC, the dressing was changed. The wound was thoroughly washed with normal saline and VAC was re-applied. The same routine was continued until a sat- 
isfactory clean wound bed was obtained for the final procedure. Skin grafting was done and after regular follow-up visits, the wound healed with good results. They concluded that VAC is a useful adjunct to the standard treatment of chronic wounds. It is an extremely simple modality and does not require expensive equipment [93]. We used a similar type of system in this study and had similar results to the above-mentioned case in most of our patients. Glaser et al. reported a dermal regenerate template in combination with negative pressure wound therapy used to reconstitute lateral abdominal wall integrity after radical debridement and control of a necrotizing soft tissue infection of the torso. Adjunctive continuous VAC therapy was used to provide external coverage and encourage the formation of granulation tissue. With this combination therapy, torso wound size decreased in surface area by $82 \%$ and the underlying musculofascial defect decreased by $64 \%$. Neovascularization of a $55 \mathrm{~cm}^{2}$ acellular dermal graft was achieved as evidenced by surface granulation and complete survival of a partial-thickness skin graft. In this patient with a complex war injury, advanced tissue replacement techniques and negative pressure wound therapy resulted in a decreased abdominal wall defect, a restoration of abdominal wall integrity/domain, and allowed for concurrent surgical treatment of complex intra-abdominal injuries [94]. Exposed tendons after burn injury create a surgical challenge for the treating physician. This is particularly true with regard to the exposed Achilles tendon. In a case report, Heugel et al. described the use of negative pressure wound therapy to facilitate coverage of the Achilles tendon. They were of the view that this therapy may provide a more appropriate therapeutic option for dealing with tendon exposure after severe burns [95]. Despite the presence of multiple reports of the success or otherwise of the VAC technique of wound care, there remains some confusion regarding its efficacy compared to conventional methods of wound dressings. In our study, we have demonstrated that VAC is statistically superior to WMD dressing in terms of reduction in surface area, reduction in volume and rate of proliferation of granulation tissue. To achieve effective and long-lasting results, a multidisciplinary approach to patient care, focused on the education and coordination of patient, family as well as medical and support staff can prove invaluable [96].

\section{Conclusion}

Acute and chronic wounds are a major problem facing medical professionals. They pose as an economic as well as emotional burden for both patients and individuals who care for them. Many types of dressings are present which may be used depending upon the indications. However, most surgeons and nurses still practice the age-old method of gauze packing of wounds. VAC provides a superior alternative to this with significantly better results in three parameters of wound healing. It is extremely useful in reducing the surface area of wounds compared to WMD ( $\mathrm{p}$ value $<0.001$ ). It is also better at reducing the volume of the wound compared to WMD ( $\mathrm{p}$ value $<0.001$ ). Further VAC has demon- 
strated better results in terms of proliferation of granulation tissue ( $\mathrm{p}$ value $<$ 0.001).

Based upon the results of our study we recommend that VAC should be used in preference to other dressings specially WMD in both acute and chronic settings. Specific wound types include deep cutaneous wounds inflicted by trauma, raw surfaces remaining after resection of tumours, following drainage and debridement of abscesses, exposed tendons and bones, following amputations especially lower limbs, diabetic ulcers, infected laparotomy wounds, high-velocity missile injuries, degloving injuries and after exploration for contaminated foreign material. However, caution should be exercised when contemplating the application of VAC to the open abdomen. The high rate of fistula formation and mortality associated with this precludes it as an indication for VAC therapy. Since there were no significant effects of the treatment, it can be used safely in all age groups and in patients with chronic diseases. Its safety and efficacy can be extended to VAC being used as an out-patient procedure as well.

\section{Conflicts of Interest}

There is no conflict of interest declared in this study.

\section{References}

[1] Madden, J.W. (1977) Textbook of Surgery. The Biological Basis of Modern Surgical Science. 11th Edition, WB Saunders and Company, Philadelphia, PA, 271.

[2] Ovington, L.G. (2002) The Evolution of Wound Management: Ancient Origins and Advances of the Past 20 Years. Home Health Nurse, 20, 652-656. https://doi.org/10.1097/00004045-200210000-00009

[3] Hinman, C.D. and Maibach, H. (2002) Effect of Air Exposure and Occlusion on Experimental Human Skin Wounds. Nature, 200, 377-378. https://doi.org/10.1038/200377a0

[4] Argenta, L.C. and Morykwas, M.J. (1997) Vacuum-Assisted Closure: A New Method for Wound Control and Treatment: Clinical Experience. Annals of Plastic Surgery, 38, 563-577. https://doi.org/10.1097/00000637-199706000-00002

[5] Morykwas, M.J., Argenta, L.C., Shelton-Brown, E.I. and McGuirt, W. (1997) Vacuum-Assisted Closure: A New Method for Wound Control and Treatment: Animal Studies and Basic Foundation. Annals of Plastic Surgery, 38, 553-562. https://doi.org/10.1097/00000637-199706000-00001

[6] Kujath, P. and Michelsen, A. (2008) Wounds-From Physiology to Wound Dressing. Deutsches Ärzteblatt International, 105, 239-248. https://doi.org/10.3238/arztebl.2008.0558

[7] Leaper, D.J. (2006) Traumatic and Surgical Wounds. British Medical Journal, 332, 532-535. https://doi.org/10.1136/bmj.332.7540.532

[8] De Lalla, F. (2006) Perioperative Antibiotic Prophylaxis: A Critical Review. Surgical Infections, 7, S37-S39. https://doi.org/10.1089/sur.2006.7.s-37

[9] Holtom, P.D. (2006) Antibiotic Prophylaxis: Current Recommendations. Journal of the American Academy of Orthopaedic Surgeons, 14, S98-S100. https://doi.org/10.5435/00124635-200600001-00023 
[10] Sanabria, A., Domínguez, L.C., Valdivieso, E. and Gómez, G. (2007) Prophylactic Antibiotics for Mesh Inguinal Hernioplasty: A Meta-Analysis. Annals of Surgery, 245, 392-396. https://doi.org/10.1097/01.sla.0000250412.08210.8e

[11] Nelson, R.L. and Glenny, A.M. (2009) Antimicrobial Prophylaxis for Colorectal Surgery. Cochrane Database of Systematic Reviews, No. 1, CD001181. https://doi.org/10.1002/14651858.CD001181.pub3

[12] Williams, N.S., Bulstrode, C.J.K. and O' Connell, P.R. (2008) Bailey and Love's Short Practice of Surgery. Surgical Infections. 25th Edition, Hodder Arnold, London, 44.

[13] Ueno, C., Hunt, T.K. and Hopf, H.W. (2006) Using Physiology to Improve Surgical Wound Outcomes. Plastic and Reconstructive Surgery, 117, 59S-71S. https://doi.org/10.1097/01.prs.0000225438.86758.21

[14] Järvinen, T.A. and Ruoslahti, E. (2007) Molecular Changes in the Vasculature of Injured Tissues. The American Journal of Pathology, 171, 702-711. https://doi.org/10.2353/ajpath.2007.061251

[15] Somanath, P.R., Chen, J. and Byzova, T.V. (2008) Akt1 Is Necessary for the Vascular Maturation and Angiogenesis during Cutaneous Wound Healing. Angiogenesis, 11, 277-288. https://doi.org/10.1007/s10456-008-9111-7

[16] Kim, M.H., Liu, W., Borjesson, D.L., Curry, F.R., Miller, L.S., Cheung, A.L., Liu, F.T., Isseroff, R.R. and Simon, S.I. (2008) Dynamics of Neutrophil Infiltration during Cutaneous Wound Healing and Infection Using Fluorescence Imaging. Journal of Investigative Dermatology, 128, 1812-1820.

https://doi.org/10.1038/sj.jid.5701223

[17] Saaristo, A., Tammela, T., Farkkilā, A., Kärkkäinen, M., Suominen, E., Yla-Herttuala, S. and Alitalo, K. (2006) Vascular Endothelial Growth Factor-C Accelerates Diabetic Wound Healing. The American Journal of Pathology, 169, 1080-1087. https://doi.org/10.2353/ajpath.2006.051251

[18] Liu, Z.J. and Velazquez, O.C. (2008) Hyperoxia, Endothelial Progenitor Cell Mobilization, and Diabetic Wound Healing. Antioxidants \& Redox Signaling, 10, 1869-1882. https://doi.org/10.1089/ars.2008.2121

[19] Velazquez, O.C. (2007) Angiogenesis and Vasculogenesis: Inducing the Growth of New Blood Vessels and Wound Healing by Stimulation of Bone Marrow-Derived Progenitor Cell Mobilization and Homing. Journal of Vascular Surgery, 45, A39-A47. https://doi.org/10.1016/j.jvs.2007.02.068

[20] Enoch, S. and Harding, K.G. (2003) Wound Bed Preparation: The Science Behind the Removal of Barriers to Healing. Wounds, 15, 213-229.

[21] Franczyk, M., Lohman, R.F., Agarwal, J.P., Rupani, G., Drum, M. and Gottlieb, L.J. (2009) The Impact of Topical Lidocaine on Pain Level Assessment during and after Vacuum-Assisted Closure Dressing Changes: A Double-Blind, Prospective, Randomized Study. Plastic and Reconstructive Surgery, 124, 854-861.

https://doi.org/10.1097/PRS.0b013e3181b038b4

[22] Grey, J.E., Enoch, S. and Harding, K.G. (2006) ABC of Wound Healing. Wound Assessment. British Medical Journal, 332, 285-288.

https://doi.org/10.1136/bmj.332.7536.285

[23] Brem, H., Stojadinovic, O., Diegelmann, R.F., Entero, H., Lee, B., Pastar, I., Golinko, M., Rosenberg, H. and Tomic-Canic, M. (2007) Molecular Markers in Patients with Chronic Wounds to Guide Surgical Debridement. Journal of Molecular Medicine, 13, Article ID: 1301030. https://doi.org/10.2119/2006-00054.Brem

[24] Anderson, J.M., Rodriguez, A. and Chang, D.T. (2008) Foreign Body Reaction to 
Biomaterials. Seminars in Immunology, 20, 86-100. https://doi.org/10.1016/j.smim.2007.11.004

[25] Hill, R.P., Kaspler, P., Griffin, A.M., O’Sullivan, B., Catton, C., Alasti, H., Abbas, A., Heydarian, M., Ferguson, P., Wunder, J.S. and Bell, R.S. (2007) Studies of the in Vivo Radiosensitivity of Human Skin Fibroblasts. Radiotherapy and Oncology, 84, 75-83. https://doi.org/10.1016/j.radonc.2007.05.025

[26] Sivamani, R.K., Pullar, C.E., Manabat-Hidalgo, C.G., Rocke, D.M., Carlsen, R.C., Greenhalgh, D.G. and Isseroff, R.R. (2009) Stress-Mediated Increases in Systemic and Local Epinephrine Impair Skin Wound Healing: Potential New Indication for Beta Blockers. PLoS Medicine, 6, e1000012.

https://doi.org/10.1371/journal.pmed.1000012

[27] Demling, R.H. (2009) Nutrition, Anabolism, and the Wound Healing Process: An Overview. Eplasty, 9, e9.

[28] Hirsch, T., Spielmann, M., Zuhaili, B., Koehler, T., Fossum, M., Steinau, H.U., Yao, F., Steinstraesser, L., Onderdonk, A.B. and Eriksson, E. (2008) Enhanced Susceptibility to Infections in a Diabetic Wound Healing Model. BMC Surgery, 8, 5. https://doi.org/10.1186/1471-2482-8-5

[29] Payne, W.G., Naidu, D.K., Wheeler, C.K., Barkoe, D., Mentis, M., Salas, R.E., Smith, D.J. and Robson, M.C. (2008) Wound Healing in Patients with Cancer. Eplasty, 8, e9.

[30] Hardman, M.J. and Ashcroft, G.S. (2008) Estrogen, Not Intrinsic Aging, Is the Major Regulator of Delayed Human Wound Healing in the Elderly. Genome Biology, 9, R80. https://doi.org/10.1186/gb-2008-9-5-r80

[31] Ashcroft, G.S., Mills, S.J., Lei, K., Gibbons, L., Jeong, M.J., Taniguchi, M., Burow, M., Horan, M.A., Wahl, S.M. and Nakayama, T. (2003) Estrogen Modulates Cutaneous Wound Healing by Downregulating Macrophage Migration Inhibitory Factor. Journal of Clinical Investigation, 111, 1309-1318. https://doi.org/10.1172/JCI200316288

[32] Rook, J.M., Hasan, W. and McCarson, K.E. (2008) Temporal Effects of Topical Morphine Application on Cutaneous Wound Healing. Anesthesiology, 109, 130-136. https://doi.org/10.1097/ALN.0b013e31817b5ac3

[33] Kuri, M., Nakagawa, M., Tanaka, H., Hasuo, S. and Kishi, Y. (2005) Determination of the Duration of Preoperative Smoking Cessation to Improve Wound Healing after Head and Neck Surgery. Anesthesiology, 102, 892-896. https://doi.org/10.1097/00000542-200505000-00005

[34] Sørensen, L.T., Hørby, J., Friis, E., Pilsgaard, B. and Jørgensen, T. (2002) Smoking as a Risk Factor for Wound Healing and Infection in Breast Cancer Surgery. European Journal of Surgical Oncology, 28, 815-820. https://doi.org/10.1053/ejso.2002.1308

[35] Gouin, J.P., Kiecolt-Glaser, J.K., Malarkey, W.B. and Glaser, R. (2008) The Influence of Anger Expression on Wound Healing. Brain, Behavior, and Immunity, 22, 699-708. https://doi.org/10.1016/j.bbi.2007.10.013

[36] Lee, J.C., Kandula, S. and Sherber, N.S. (2009) Beyond Wet-to-Dry: A Rational Approach to Treating Chronic Wounds. Eplasty, 9, e14.

[37] Beam, J.W. (2008) Occlusive Dressings and the Healing of Standardized Abrasions. Journal of Athletic Training, 43, 600-607. https://doi.org/10.4085/1062-6050-43.6.600

[38] Menke, M.N., Menke, N.B., Boardman, C.H. and Diegelmann, R.F. (2008) Biologic Therapeutics and Molecular Profiling to Optimize Wound Healing. Gynecologic 
Oncology, 111, S87-S91. https://doi.org/10.1016/j.ygyno.2008.07.052

[39] Simhon, D., Halpern, M., Brosh, T., Vasilyev, T., Ravid, A., Tennenbaum, T., Nevo, Z. and Katzir, A. (2007) Immediate Tight Sealing of Skin Incisions Using an Innovative Temperature-Controlled Laser Soldering Device: In Vivo Study in Porcine skin. Annals of Surgery, 245, 206-213. https://doi.org/10.1097/01.sla.0000232554.13719.10

[40] Swartz, M.N. (2004) Clinical Practice. Cellulitis. The New England Journal of Medicine, 350, 904-912. https://doi.org/10.1056/NEJMcp031807

[41] Enoch, S., Grey, J.E. and Harding, K.G. (2006) ABC of Wound Healing. Non-Surgical and Drug Treatments. British Medical Journal, 332, 900-903. https://doi.org/10.1136/bmj.332.7546.900

[42] Fong, J. and Wood, F. (2006) Nanocrystalline Silver Dressings in Wound Management: A Review. International Journal of Nanomedicine, 1, 441-449.

[43] Small, G.R., Hadoke, P.W., Sharif, I., Dover, A.R., Armour, D., Kenyon, C.J., Gray, G.A. and Walker, B.R. (2005) Preventing Local Regeneration of Glucocorticoids by 11Beta-Hydroxysteroid Dehydrogenase Type 1 Enhances Angiogenesis. Proceedings of the National Academy of Sciences of the United States of America, 102, 12165-12170. https://doi.org/10.1073/pnas.0500641102

[44] Chiang, B., Essick, E., Ehringer, W., Murphree, S., Hauck, M.A., Li, M. and Chien, S. (2007) Enhancing Skin Wound Healing by Direct Delivery of Intracellular Adenosine Triphosphate. The American Journal of Surgery, 193, 213-218. https://doi.org/10.1016/j.amjsurg.2006.08.069

[45] Cantürk, N.Z., Vural, B., Esen, N., Cantürk, Z., Oktay, G., Kirkali, G. and Solakoglu, S. (1999) Effects of Granulocyte-Macrophage Colony-Stimulating Factor on Incisional Wound Healing in an Experimental Diabetic Rat Model. Endocrine Research, 25, 105-116. https://doi.org/10.3109/07435809909066133

[46] Eming, S.A., Krieg, T. and Davidson, J.M. (2007) Gene Therapy and Wound Healing. Clinics in Dermatology, 25, 79-92.

https://doi.org/10.1016/j.clindermatol.2006.09.011

[47] Cianfarani, F., Zambruno, G., Brogelli, L., Sera, F., Lacal, P.M., Pesce, M., Capogrossi, M.C., Failla, C.M., Napolitano, M. and Odorisio, T. (2006) Placenta Growth Factor in Diabetic Wound Healing: Altered Expression and Therapeutic Potential. The American Journal of Pathology, 169, 1167-1182. https://doi.org/10.2353/ajpath.2006.051314

[48] Metcalfe, A.D. and Ferguson, M.W. (2007) Tissue Engineering of Replacement Skin: The Crossroads of Biomaterials, Wound Healing, Embryonic Development, Stem Cells and Regeneration. Journal of the Royal Society Interface, 4, 413-437. https://doi.org/10.1098/rsif.2006.0179

[49] Mano, J.F., Silva, G.A., Azevedo, H.S., Malafaya, P.B., Sousa, R.A., Silva, S.S., Boesel, L.F., Oliveira, J.M., Santos, T.C., Marques, A.P., Neves, N.M. and Reis, R.L. (2007) Natural Origin Biodegradable Systems in Tissue Engineering and Regenerative Medicine: Present Status and Some Moving Trends. Journal of the Royal Society Interface, 4, 999-1030. https://doi.org/10.1098/rsif.2007.0220

[50] Majtan, J. and Majtan, V. (2009) Is Manuka Honey the Best Type of Honey for Wound Care? Journal of Hospital Infection, 74, 305-306. https://doi.org/10.1016/j.jhin.2009.08.010

[51] Dunwoody, G. and Acton, C. (2008) The Use of Medical Grade Honey in Clinical Practice. British Journal of Nursing, 17, S38-S44.

https://doi.org/10.12968/bjon.2008.17.Sup9.31665 
[52] Simon, A., Traynor, K., Santos, K., Blaser, G., Bode, U. and Molan, P. (2009) Medical Honey for Wound Care-Still the 'Latest Resort'? Evidence-Based Complementary and Alternative Medicine, 6, 165-173. https://doi.org/10.1093/ecam/nem175

[53] Johnston, C.S. and Gaas, C.A. (2006) Vinegar: Medicinal Uses and Antiglycemic Effect. Medscape General Medicine, 8, 61.

[54] Jones, V., Grey, J.E. and Keith, G.H. (2006) ABC of Wound Healing. Wound Dressings. British Medical Journal, 332, 900-903. https://doi.org/10.1136/bmj.332.7546.900

[55] Dinah, F. and Adhikari, A. (2006) Gauze Packing of Open Surgical Wounds: Empirical or Evidence-Based Practice? Annals of the Royal College of Surgeons of England, 88, 33-36. https://doi.org/10.1308/003588406X83014

[56] Worley, C.A. (2006) So, What Do I Put on This Wound? Making Sense of the Wound Dressing Puzzle: Part II. MEDSURG Nursing. The Journal of Adult Health, 15, 182-183.

[57] Lohmann, M., Thomsen, J.K., Edmonds, M.E., Harding, K.G., Apelqvist, J. and Gottrup, F. (2004) Safety and Performance of a New Non-Adhesive Foam Dressing for the Treatment of Diabetic Foot Ulcers. Journal of Wound Care, 13, 118-120. https://doi.org/10.12968/jowc.2004.13.3.26591

[58] Gist, S., Tio-Matos, I., Falzgraf, S., Cameron, S. and Beebe, M. (2009) Wound Care in the Geriatric Client. Clinical Interventions in Aging, 4, 269-287. https://doi.org/10.2147/CIA.S4726

[59] Beam, J.W. (2007) Management of Superficial to Partial-Thickness Wounds. Journal of Athletic Training, 42, 422-424.

[60] Timmers, M.S., Le Cessie, S., Banwell, P. and Jukema, G.N. (2005) The Effects of Varying Degrees of Pressure Delivered by Negative-Pressure Wound Therapy on Skin Perfusion. Annals of Plastic Surgery, 55, 665-671. https://doi.org/10.1097/01.sap.0000187182.90907.3d

[61] Webb, L.X. and Pape, H.C. (2008) Current Thought Regarding the Mechanism of Action of Negative Pressure Wound Therapy with Reticulated Open Cell Foam. Journal of Orthopaedic Trauma, 22, S135-S137. https://doi.org/10.1097/BOT.0b013e31818956ce

[62] Saxena, V., Hwang, C.W., Huang, S., Eichbaum, Q., Ingber, D. and Orgill, D.P. (2004) Vacuum-Assisted Closure: Microdeformations of Wounds and Cell Proliferation. Plastic and Reconstructive Surgery, 114, 1086-1096. https://doi.org/10.1097/01.PRS.0000135330.51408.97

[63] Stechmiller, J.K., Childress, B., Stevens, G., Kilpadi, D.V. and Schultz, G.S. (2008) Effect of Negative Pressure Wound Therapy on the Expression of TNF- $\alpha$, IL- $1 \beta$, MMP-2, MMP-3, and TIMP-1 in Wound Fluid of Adults with Pressure Ulcers. Wound Repair and Regeneration, 13, A4-A27. https://doi.org/10.1111/j.1067-1927.2005.130215az.x

[64] Singh, S., Mackey, S. and Soldin, M. (2008) VAC It-Some Techniques on the Application of VAC Dressings. Annals of the Royal College of Surgeons of England, 90, 161-162. https://doi.org/10.1308/rcsann.2008.90.2.161

[65] Danino, A.M. and Coeugniet, E. (2008) Negative Pressure Dressing: Some Background to a Monopole Business. Eplasty, 8, e6.

[66] Sauerbruch, F. (1952) Mes souvenirs de chirurgien. Presses Denoël, Paris.

[67] Chen, S.Z., Li, J., Li, X.-Y. and Xu, L.-S. (2005) Effects of Vacuum-Assisted Closure 
on Wound Microcirculation: An Experimental Study. Asian Journal of Surgery, 28, 211-217. https://doi.org/10.1016/S1015-9584(09)60346-8

[68] Kloeters, O., Schierle, C., Tandara, A. and Mustoe, T.A. (2008) The Use of a Semi-Occlusive Dressing Reduces Epidermal Inflammatory Cytokine Expression and Mitigates Dermal Proliferation and Inflammation in a Rat Incisional Model. Wound Repair and Regeneration, 16, 568-575. https://doi.org/10.1111/j.1524-475X.2008.00404.x

[69] Bovill, E., Banwell, P.E., Teot, L., Eriksson, E., Song, C., Mahoney, J., Gustafsson, R., Horch, R., Deva, A. and Whitworth, I. (2008) Topical Negative Pressure Wound Therapy: A Review of Its Role and Guidelines for Its Use in the Management of Acute Wounds. International Wound Journal, 5, 511-529. https://doi.org/10.1111/j.1742-481X.2008.00437.x

[70] Mendonca, D.A., Papini, R. and Price, P.E. (2006) Negative-Pressure Wound Therapy: A Snapshot of the Evidence. International Wound Journal, 3, 261-271. https://doi.org/10.1111/j.1742-481X.2006.00266.x

[71] Perez, D., Bramkamp, M., Exe, C., von Ruden, C. and Ziegler, A. (2009) Modern Wound Care for the Poor: A Randomized Clinical Trial Comparing the Vacuum System with Conventional Saline-Soaked Gauze Dressings. The American Journal of Surgery, 199, 14-20. https://doi.org/10.1016/j.amjsurg.2008.12.029

[72] Fischer, J.E. (2008) A Cautionary Note: The Use of Vacuum-Assisted Closure Systems in the Treatment of Gastrointestinal Cutaneous Fistula May Be Associated with Higher Mortality from Subsequent Fistula Development. The American Journal of Surgery, 196, 1-2. https://doi.org/10.1016/j.amjsurg.2008.01.001

[73] Bee, T.K., Croce, M.A., Magnotti, L.J., Zarzaur, B.L., Maish, G.O., Minard, G., Schroeppel, T.J. and Fabian, T.C. (2008) Temporary Abdominal Closure Techniques: A Prospective Randomized Trial Comparing Polyglactin 910 Mesh and Vacuum-Assisted Closure. The Journal of Trauma: Injury, Infection, and Critical Care, 65, 337-344. https://doi.org/10.1097/TA.0b013e31817fa451

[74] Thompson, J.T. and Marks, M.W. (2007) Negative Pressure Wound Therapy. Clinics in Plastic Surgery, 34, 673-684. https://doi.org/10.1016/j.cps.2007.07.005

[75] Noble-Bell, G. and Forbes, A. (2008) A Systematic Review of the Effectiveness of Negative Pressure Wound Therapy in the Management of Diabetes Foot Ulcers. International Wound Journal, 5, 233-242. https://doi.org/10.1111/j.1742-481X.2008.00430.x

[76] Blume, P.A., Walters, J., Payne, W., Ayala, J. and Lantis, J. (2008) Comparison of Negative Pressure Wound Therapy Using Vacuum-Assisted Closure with Advanced Moist Wound Therapy in the Treatment of Diabetic Foot Ulcers: A Multicenter Randomized Controlled Trial. Diabetes Care, 31, 631-636. https://doi.org/10.2337/dc07-2196

[77] Fife, C.E., Walker, D., Thomson, B. and Otto, G. (2008) The Safety of Negative Pressure Wound Therapy Using Vacuum-Assisted Closure in Diabetic Foot Ulcers Treated in the Outpatient Setting. International Wound Journal, 5, 17-22. https://doi.org/10.1111/j.1742-481X.2008.00467.x

[78] Ferreira, M.C., Carvalho, V.F., Kamamoto, F., Tuma Jr., P. and Paggiaro, A.O. (2009) Negative Pressure Therapy (Vacuum) for Wound Bed Preparation among Diabetic Patients: Case Series. Sao Paulo Medical Journal, 127, 166-170. https://doi.org/10.1590/S1516-31802009000300010

[79] Zannis, J., Angobaldo, J., Marks, M., DeFranzo, A., David, L., Molnar, J. and Argenta, L. (2009) Comparison of Fasciotomy Wound Closures Using Traditional 
Dressing Changes and the Vacuum-Assisted Closure Device. Annals of Plastic Surgery, 62, 407-409. https://doi.org/10.1097/SAP.0b013e3181881b29

[80] Cresti, S., Ouaïssi, M., Sielezneff, I., Chaix, J.B., Pirro, N., Berthet, B., Consentino, B. and Sastre, B. (2008) Advantage of Vacuum Assisted Closure on Healing of Wound Associated with Omentoplasty after Abdominoperineal Excision: A Case Report. World Journal of Surgical Oncology, 6, 136. https://doi.org/10.1186/1477-7819-6-136

[81] Le Franc, B., Sellal, O., Grimandi, G. and Duteille, F. (2009) Cost-Effectiveness Analysis of Vacuum-Assisted Closure in the Surgical Wound Bed Preparation of Soft Tissue Injuries. Annales de Chirurgie Plastique Esthétique, 55, 195-203.

[82] de Leon, J.M., Barnes, S., Nagel, M., Fudge, M., Lucius, A. and Garcia, B. (2009) Cost-Effectiveness of Negative Pressure Wound Therapy for Postsurgical Patients in Long-Term Acute Care. Advances in Skin \& Wound Care, 22, 122-127. https://doi.org/10.1097/01.ASW.0000305452.79434.d9

[83] Senchenkov, A., Petty, P.M., Knoetgen, J., Moran, S.L., Johnson, C.H. and Clay, R.P. (2007) Outcomes of Skin Graft Reconstructions with the Use of Vacuum Assisted Closure (VAC(R)) Dressing for Irradiated Extremity Sarcoma Defects. World Journal of Surgical Oncology, 5, 138. https://doi.org/10.1186/1477-7819-5-138

[84] Llanos, S., Danilla, S., Barraza, C., Armijo, E., Piñeros, J.L., Quintas, M., Searle, S. and Calderon, W. (2006) Effectiveness of Negative Pressure Closure in the Integration of Split Thickness Skin Grafts: A Randomized, Double-Masked, Controlled Trial. Annals of Surgery, 244, 700-705. https://doi.org/10.1097/01.sla.0000217745.56657.e5

[85] Moisidis, E., Heath, T., Boorer, C., Ho, K. and Deva, A.K. (2004) A Prospective, Blinded, Randomized, Controlled Clinical Trial of Topical Negative Pressure Use in Skin Grafting. Plastic and Reconstructive Surgery, 114, 917-922. https://doi.org/10.1097/01.PRS.0000133168.57199.E1

[86] Khan, F.A., Farooq, M.U. and Zafar, H. (2006) Chest Wall Defects and Their Reconstruction. Annals of KEMU, 12, 12-14. https://doi.org/10.21649/akemu.v12i1.814

[87] Stannard, J.P., Volgas, D.A., Stewart, R., McGwin Jr., G. and Alonso, J.E. (2009) Negative Pressure Wound Therapy after Severe Open Fractures: A Prospective Randomized Study. Journal of Orthopaedic Trauma, 23, 552-557. https://doi.org/10.1097/BOT.0b013e3181a2e2b6

[88] Stannard, J.P., Robinson, J.T., Anderson, E.R., McGwin Jr., G., Volgas, D.A. and Alonso, J.E. (2006) Negative Pressure Wound Therapy to Treat Hematomas and Surgical Incisions Following High-Energy Trauma. The Journal of Trauma: Injury, Infection, and Critical Care, 60, 1301-1306. https://doi.org/10.1097/01.ta.0000195996.73186.2e

[89] Wong, L.K., Nesbit, R.D., Turner, L.A. and Sargent, L.A. (2006) Management of a Circumferential Lower Extremity Degloving Injury with the Use of Vacuum-Assisted Closure. The Southern Medical Journal, 99, 628-630. https://doi.org/10.1097/01.smj.0000217111.35160.09

[90] Braakenburg, A., Obdeijn, M.C., Feitz, R., van Rooij, I.A., van Griethuysen, A.J. and Klinkenbijl, J.H. (2006) The Clinical Efficacy and Cost Effectiveness of the Vacuum-Assisted Closure Technique in the Management of Acute and Chronic Wounds: A Randomized Controlled Trial. Plastic and Reconstructive Surgery, 118, 390-397. https://doi.org/10.1097/01.prs.0000227675.63744.af

[91] Vuerstaek, J.D., Vainas, T., Wuite, J., Nelemans, P., Neumann, M.H. and Veraart, 
J.C. (2006) State-of-the-Art Treatment of Chronic Leg Ulcers: A Randomized Controlled Trial Comparing Vacuum-Assisted Closure (V.A.C.) with Modern Wound Dressings. Journal of Vascular Surgery, 44, 1029-1037.

https://doi.org/10.1016/j.jvs.2006.07.030

[92] Caniano, D.A., Ruth, B. and Teich, S. (2005) Wound Management with Vacuum-Assisted Closure: Experience in 51 Pediatric Patients. Journal of Pediatric Surgery, 40, 128-132. https://doi.org/10.1016/j.jpedsurg.2004.09.016

[93] Ahmad, M. and Malik, S.A. (2008) Vacuum Assisted Closure Therapy: Revisited. Rawal Medical Journal, 33, 121-122.

[94] Glaser, J.J., Sheppard, F.R., Gage, F.A., Kumar, A.R., Liston, W.A., Elster, E.A., Dunne, J.R. and Blankenship, C.L. (2009) Warfare-Related Complex Abdominal Wall Reconstruction Using a Bioprosthetic Regenerate Template and Negative Pressure Therapy. Eplasty, 9, e17.

[95] Heugel, J.R., Parks, K.S., Christie, S.S., Pulito, J.F., Zegzula, D.H. and Kemalyan, N.A. (2002) Treatment of the Exposed Achilles Tendon Using Negative Pressure Wound Therapy: A Case Report. Journal of Burn Care \& Research, 23, 167-171. https://doi.org/10.1097/00004630-200205000-00005

[96] Werdin, F., Tennenhaus, M., Schaller, H.E. and Rennekampff, H.O. (2009) Evidence-Based Management Strategies for Treatment of Chronic Wounds. Eplasty, 9 , e19. 


\section{Performa}

PC Number:

Name:

Age:

Sex:

Address:

Etiology of Ulcer:

Type of dressing: VAC WMD

Dimensions of the wound

Size Depth Granulation tissue

$(\mathrm{cm})(\mathrm{cm})$ (\% of ulcer bed)

Day 0:

Day 3:

Day 5:

Day 7:

Day 9:

Day 11:

Day 13:

Day 15:

Total duration of hospital stay: 